\title{
Theoretical analysis of the oscillating circular piston positive displacement flowmeter: II numerical solution of equations of motion and comparison with experimental data
}

\author{
Charlotte E Morton, Ian M Hutchings \& Roger C Baker \\ Institute for Manufacturing, Department of Engineering, University of Cambridge, 17 \\ Charles Babbage Road, Cambridge CB3 0FS
}

\begin{abstract}
In the first part of this paper [1] we identified the forces and equations required to model the motion of the oscillating piston flowmeter. In this paper we discuss the method of solution, and the computational procedure for modelling the dynamic behaviour of the meter. We have, then, compared the model results with experimental data for variation in: angular velocity, vertical movement and pressure losses. We consider the agreement for variation in the following parameters: flow rate, piston mass, surface coating, lubrication holes, slots in piston skirt, length of up- and downstream pipe work, fluid viscosity and fluid density. We also compare the theory with data from two other sizes of meter. The predictions from the model are generally very accurate, although there is still potential to refine the model and increase further our understanding of the forces which contribute to the motion.
\end{abstract}

Keywords: positive displacement flowmeter, oscillating piston flowmeter, rotary piston flowmeter, theoretical model of piston movement and pressure losses.

Corresponding author: Roger C Baker

E-mail address: rcb29@cam.ac.uk 


\section{Introduction}

In the first part of this paper [1] we considered the motion of the oscillating piston and the equations which governed its motion. We identified various forces which are relevant. In this part of the paper we describe the process of calculation and discuss the agreement between the theory and the experimental data. Fuller details of this research have been provided by Morton [2].

\subsection{The oscillating piston positive displacement flowmeter}

The components of the flowmeter, sometimes referred to as a rotary piston flowmeter, are illustrated in Fig. 1. The piston, which is cylindrical and may be referred to as a rotor, oscillates within the measuring chamber with clearances between the surfaces of the piston and chamber. The size of the clearances is defined by the geometry of both the piston and the measuring chamber and influenced by the forces between the two surfaces. The size of the clearances will control both the frictional force and the leakage which occurs in all positive displacement flowmeters.

Pressure forces between the surfaces of the piston and measuring chamber cause the motion of the piston. Part I of the paper [1] described calculations of the magnitude of the pressure forces and the model used for the frictional forces opposing the piston motion, and applied Newton's second law to the motion of the piston in the tangential, radial and vertical directions, due to these forces and to gravity. This paper compares the calculations with experimental data obtained with a gravity-driven flow rig as shown schematically in Fig. 10 of Part I. Further details of the measurement of flow rate of the meter can be found in Morton et al [5], and earlier papers on this research project. 


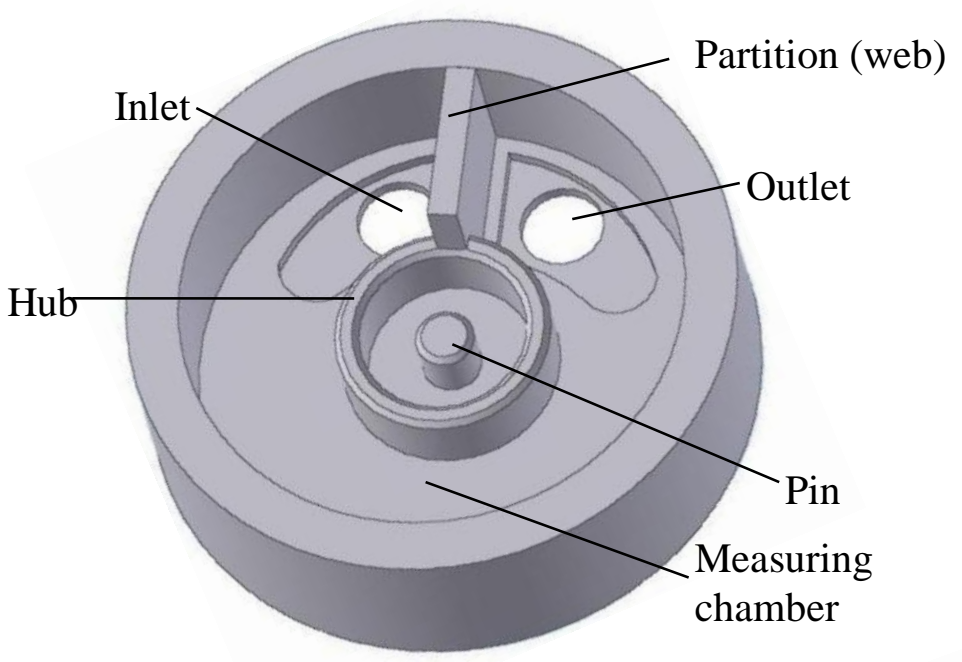

(a)


(c)

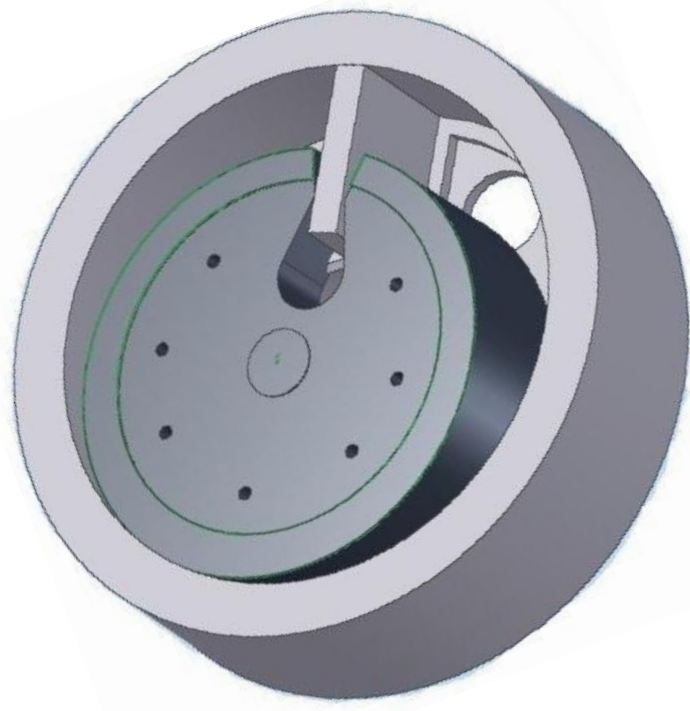

(d)

Fig. 1 Diagram of the oscillating piston flowmeter (a) measuring chamber; (b) piston from above; (c) piston from side; (d) piston located within measuring chamber. 


\subsection{Parameters varied to compare predictions with test data}

The predictions were compared with experimental data published elsewhere [2, $3 \& 4]$ for:

a) Angular velocity

b) Vertical movement

c) Pressure losses

The amount of liquid which passes through the flowmeter unmetered is called leakage. The leakage model has been given by Morton [2] and experimental data also by Morton et al [5].

This paper considers the effect of changes in some or all of the following parameters:
a) Flow rate
b) Piston mass
c) Surface coating
d) Lubrication holes
e) Slots in piston skirt
f) Length of up- and downstream pipework
g) Fluid viscosity
h) Fluid density

The use of three different materials for the piston allowed the effect of piston mass to be explored, as shown in Table 1. To examine the effect of friction between the piston and the chamber (in all cases made from type 316 stainless steel: 316SS), and to explore the possible benefits of a low friction coating, a bonded molybdenum disulfide $\left(\mathrm{MoS}_{2}\right)$ coating (Molykote) was applied to the 316SS piston for some tests. The coefficient of friction was measured as described in [2] with a laboratory rig [6] to an uncertainty of \pm 0.03 with a $95 \%$ confidence level. The friction coefficient for the uncoated 316SS piston material against $316 \mathrm{SS}$ in water was 0.36 , and with the low friction coating applied to one surface it was 0.12 .

Error bars shown on the experimental results are intended to indicate measurement uncertainty with $95 \%$ confidence levels [2]. The methods used to measure density, viscosity 
and pressure, and estimates of the associated measurement errors, are described in a previous paper [3]. 
Table 1 Material, density and mass of oscillating pistons

\begin{tabular}{|l|l|l|}
\hline Material & $\begin{array}{l}\text { Density } \\
\left(\mathrm{kg} / \mathrm{m}^{3}\right)\end{array}$ & $\begin{array}{l}\text { Mass } \\
(\mathrm{g})\end{array}$ \\
\hline carbon & 2000 & 6 \\
\hline 316 stainless steel & 8000 & 24 \\
\hline PMMA & 1200 & 3.6 \\
\hline
\end{tabular}

The results from the model were compared with those obtained experimentally using an MF30 meter provided by Litre Meter Limited as well as two other sizes of meter which were also tested in the water flow rig with carbon pistons, for:

a) Angular velocity variation

b) Pressure losses

The properties of a fourth size of meter (LF05, Table 2), were used in the model to examine the effect of a change to Equation 7 in our previous paper [1]. All the meters used are listed in Table 2.

Table 2 Flowmeters used and developed from the model (type numbers from Litre Meter Limited)

\begin{tabular}{|l|l|}
\hline Type of flowmeter & Maximum flow rate* \\
\hline VFF4 (viscous fluid flow) & $240 \mathrm{dm}^{3} / \mathrm{h}$ \\
\hline MF30 (medium flow) 1.5 & $90 \mathrm{dm}^{3} / \mathrm{h}$ \\
\hline LF15 (low flow) & $50 \mathrm{dm}^{3} / \mathrm{h}$ \\
\hline LF05 (very low flow) & $15 \mathrm{dm}^{3} / \mathrm{h}$ (developed from theoretical \\
& model) \\
\hline
\end{tabular}

* Maximum flow rates when experimental measurements were carried out. 


\section{The dynamic model}

\subsection{Initialising the model}

The dynamic model combined the force and friction models previously described [1], with the geometric model, and was solved using MATLAB to apply a time-stepping approach. The outline for the model is given in Fig. 2 .

The time step needed to be selected such that the model was stable. If too large a time step were chosen, the results could be unstable, or an inaccurate solution produced due to the loss of real variation. Smaller time steps would provide a more accurate solution but at the expense of computing time. Fig. 3 compares the model pressure loss prediction for four different time steps. For time steps less than $0.25 \mathrm{~ms}$, there was little change, but as the time step became greater than $0.25 \mathrm{~ms}$, the smaller variations were lost. For time steps of more than $2 \mathrm{~ms}$, the model crashed. The time step selected was, therefore, $0.25 \mathrm{~ms}$. 


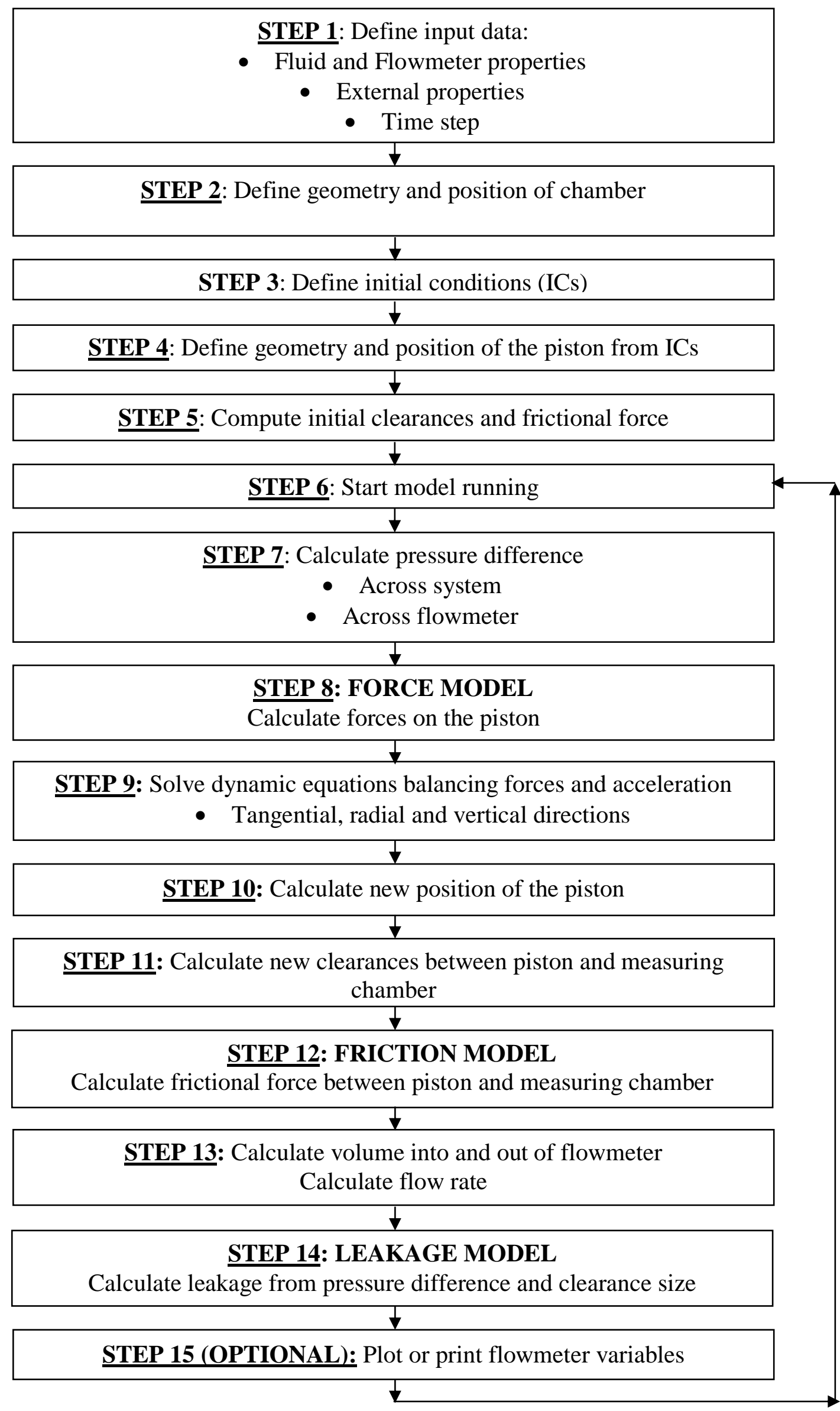

Fig. 2 Numerical solution procedure for the dynamic flowmeter model 


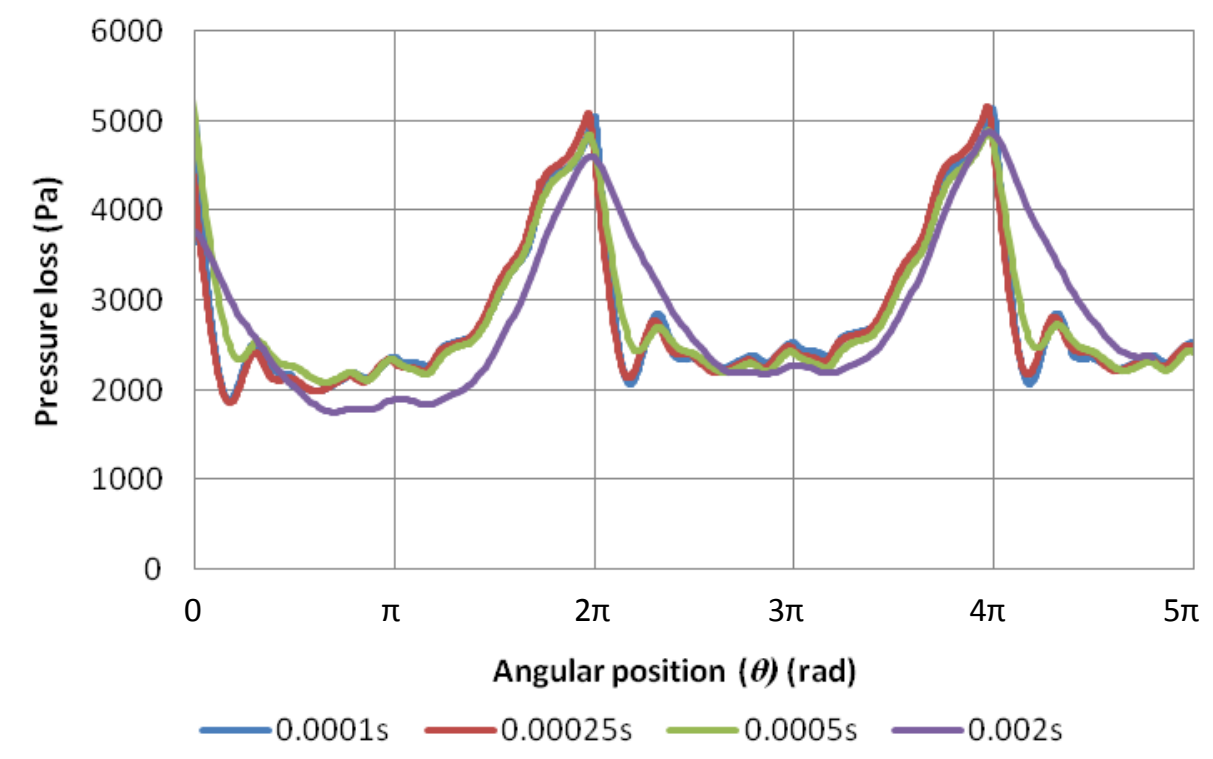

Fig. 3 Effect of computational time step on the calculated pressure difference across the flowmeter

The initial conditions were then defined. They were chosen so that the piston was at TDC $(\theta=0)$, was stationary and sat at the bottom of the measuring chamber (which was horizontal). The radius of rotation was chosen such that the piston sat centrally, and the minimum clearance between the peg and pin was equal to the minimum clearance between the peg and inner surface of the hub. The model was a dynamic model and included forces in the tangential, radial and vertical direction, which resulted in movement of the piston. The results from the model were unaffected by the initial conditions and after a number of rotations/oscillations the positioning of the piston was the same regardless of its initial position. The model was run with the piston initially located at five vertical positions, from contact with the bottom of the measuring chamber to contact with the cap. After one rotation/oscillation the position of the piston was found to be unaffected by its initial position. From the initial conditions, the initial position of the piston could be defined, clearances could be computed between the piston and measuring chamber and the frictional force calculated from the clearances. 


\subsection{Stepping through the program}

The main section of the model was embodied in a loop which enabled the values of each variable to be calculated at each time step. The time step will have implications related to the velocity and movement of liquid and piston. However, the key requirement is that the detailed fluctuation during the rotation of the piston will be correctly calculated.

The next step was to calculate the leakage, which was obtained from the size of the clearances, the pressure difference across the piston, the velocity of the piston and the viscosity of the liquid being metered.

An optional step allowed a particular variable to be printed or plotted during the run allowing it to be monitored. The model could be stopped either manually or by programming it to stop at a particular time or angular position.

\section{Experimental Validation}

\subsection{Variation due to parametric changes for the MF30 meter}

The theoretical and experimental results for two different flow rates with the carbon piston are given in Fig. 4. The angular velocity is normalised against time by taking the ratio of the instantaneous velocity over the time averaged velocity. At high flow rates there was good agreement between the theoretical and experimental variation. The range of angular velocities 
agreed, as did the angular positions for maximum and minimum. As the flow rate was reduced the agreement was less good. There was a deceleration observed just before TDC and although this was also predicted theoretically, the amount of deceleration predicted was significantly less. It is also apparent that at low flow rates $\left(8 \mathrm{dm}^{3} / \mathrm{h}\right.$ or less) there were smaller-scale variations in the angular velocity. The piston appeared to exhibit 'slip-stick' motion. The theoretical model did not model this and the theoretical results are smoother curves. 




$\longrightarrow$ Experimental results $\longrightarrow$ Theoretical results

(a)



(b)

Fig. 4 Comparison between the experimental and theoretical variations in angular velocity with angular position $(\theta)$ during one oscillation of the carbon piston in a water flow at two different flow rates: (a) 80 $\mathrm{dm}^{3} / \mathrm{h}$; (b) $8 \mathrm{dm}^{3} / \mathrm{h}$. 
Results for three different piston masses (i.e. PMMA, carbon and 316 SS pistons as listed in Table 1) are shown at $80 \mathrm{dm}^{3} / \mathrm{h}$ in Fig. 5 and at $16 \mathrm{dm}^{3} / \mathrm{h}$ in Fig. 6 . The model gave good agreement with the experimental results at higher flow rates, particularly with the lighter pistons. Experimentally, as the mass of the piston increased, the variation in the angular velocity decreased and the theory reflected this. The model predicted a longer and slower acceleration of the $316 \mathrm{SS}$ piston before TDC than was observed in the experiments, Fig. 5(c).

As the flow rate decreased, Fig. 6, the variation in angular velocity also decreased and again this was predicted by the model. However, a deceleration was observed experimentally just before TDC which increased with an increase in piston mass. The theoretical results, while predicting a small deceleration, do not predict a similar increase with piston mass. This may suggest that the forces in the theoretical model need to be further refined at this angular position where the more massive piston appeared to experience a larger deceleration force. 


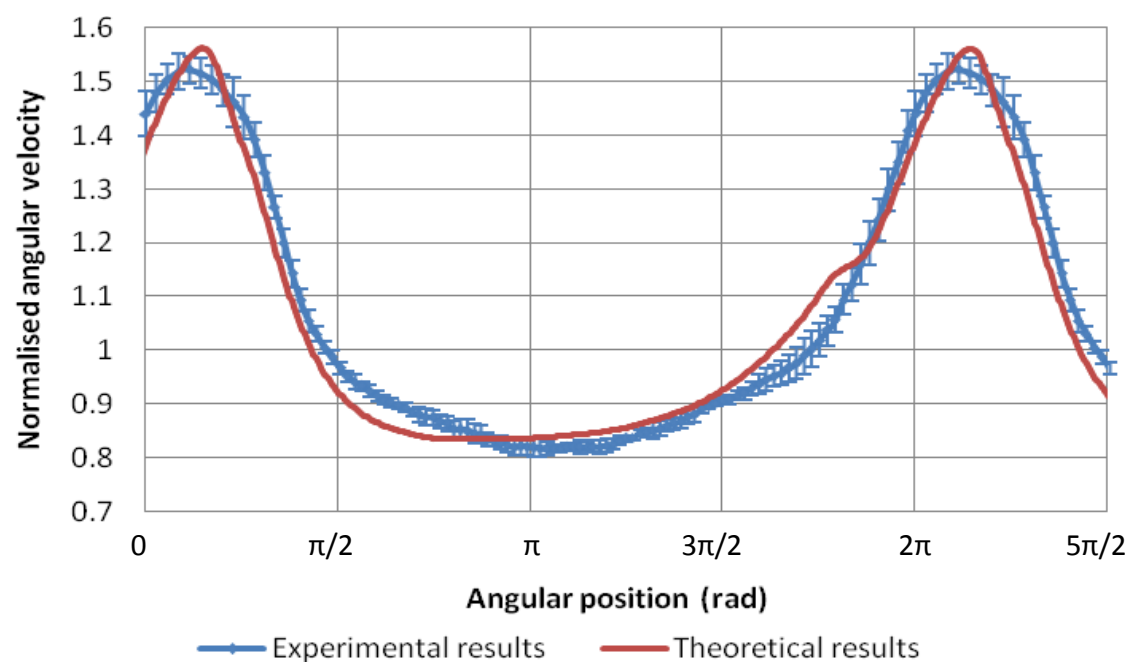

(a)

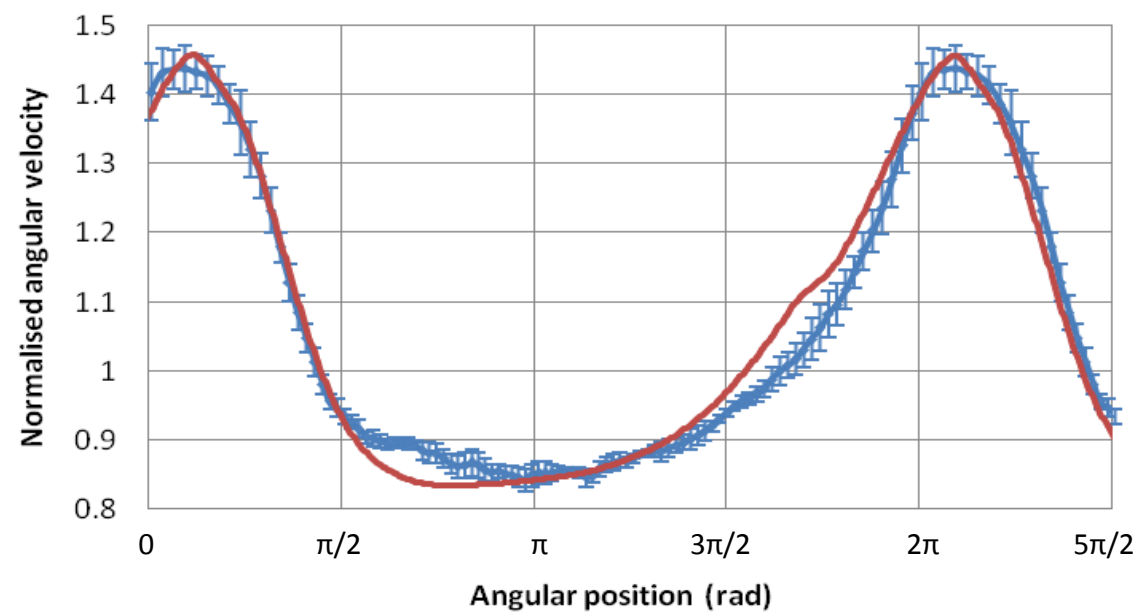

- Experimental results Theoretical results

(b)

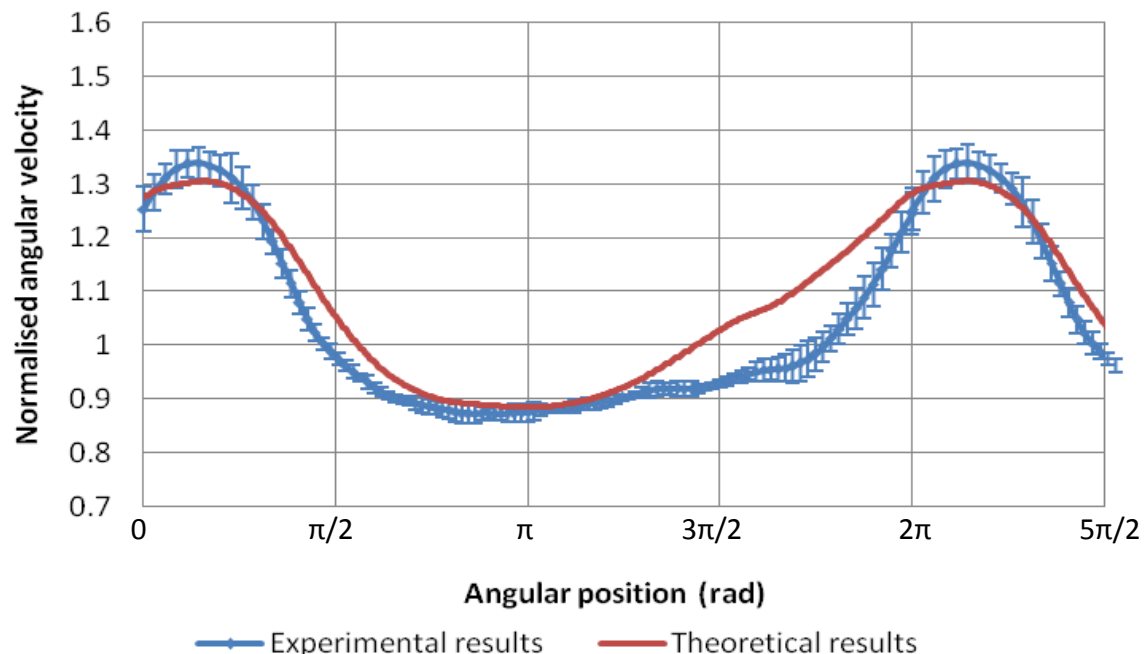

(c)

Fig. 5 Comparison between the experimental and theoretical variations in angular velocity with angular

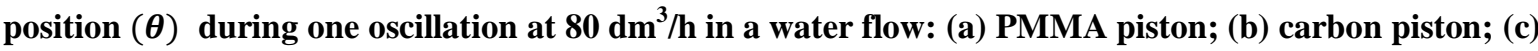
316 SS piston with low-friction coating. 


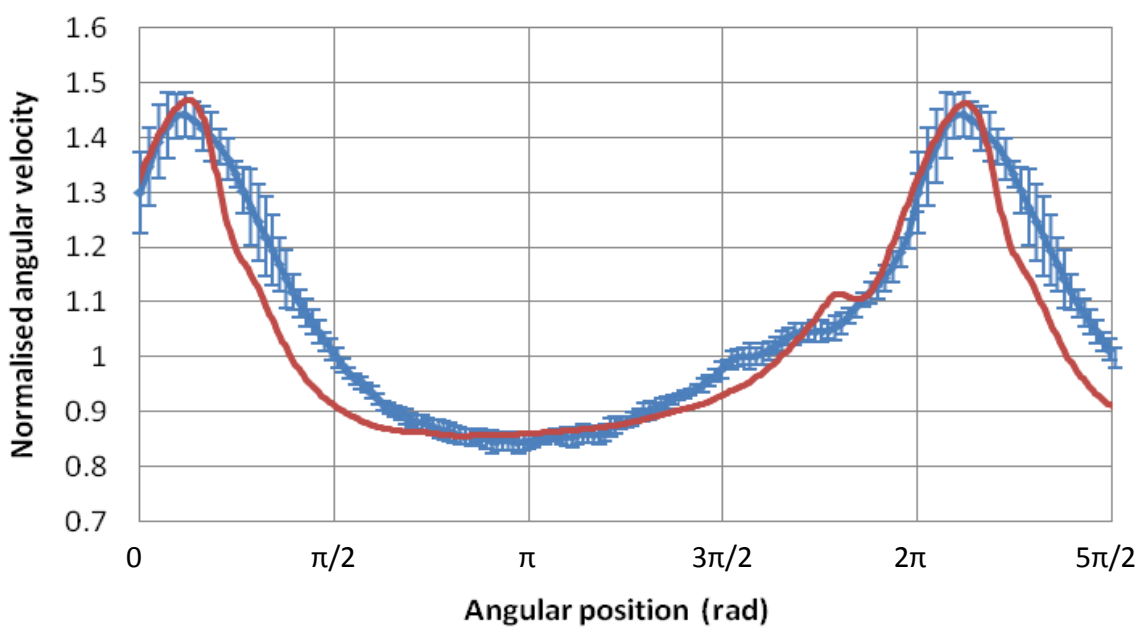

—Experimental results $\quad$ Theoretical results

(a)

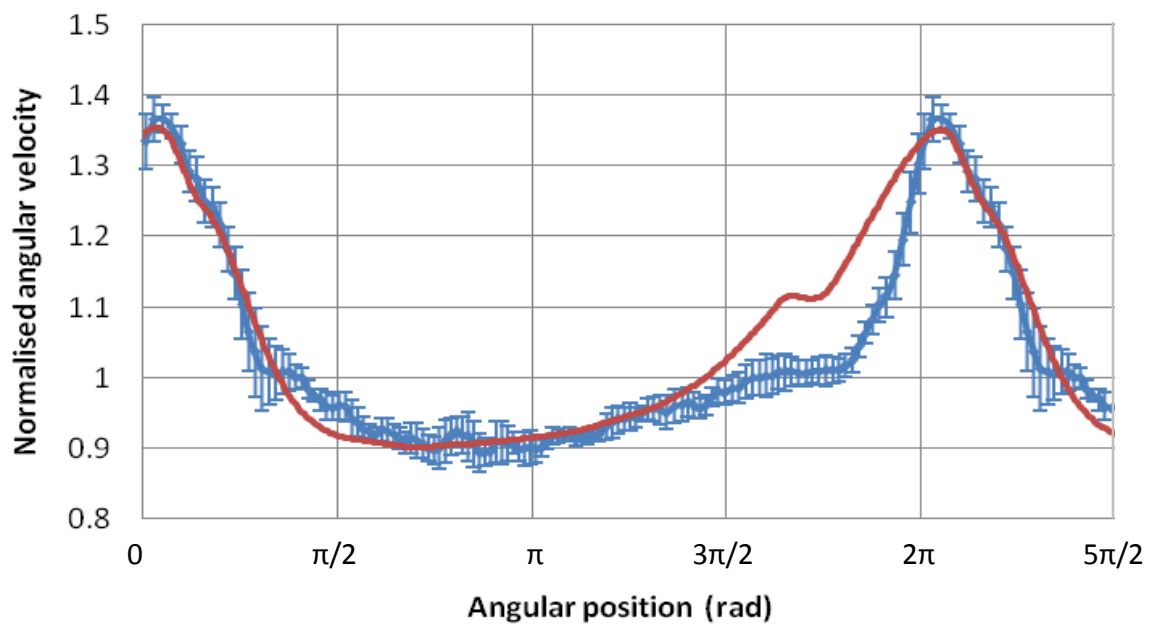

- Experimental results Theoretical results

(b)

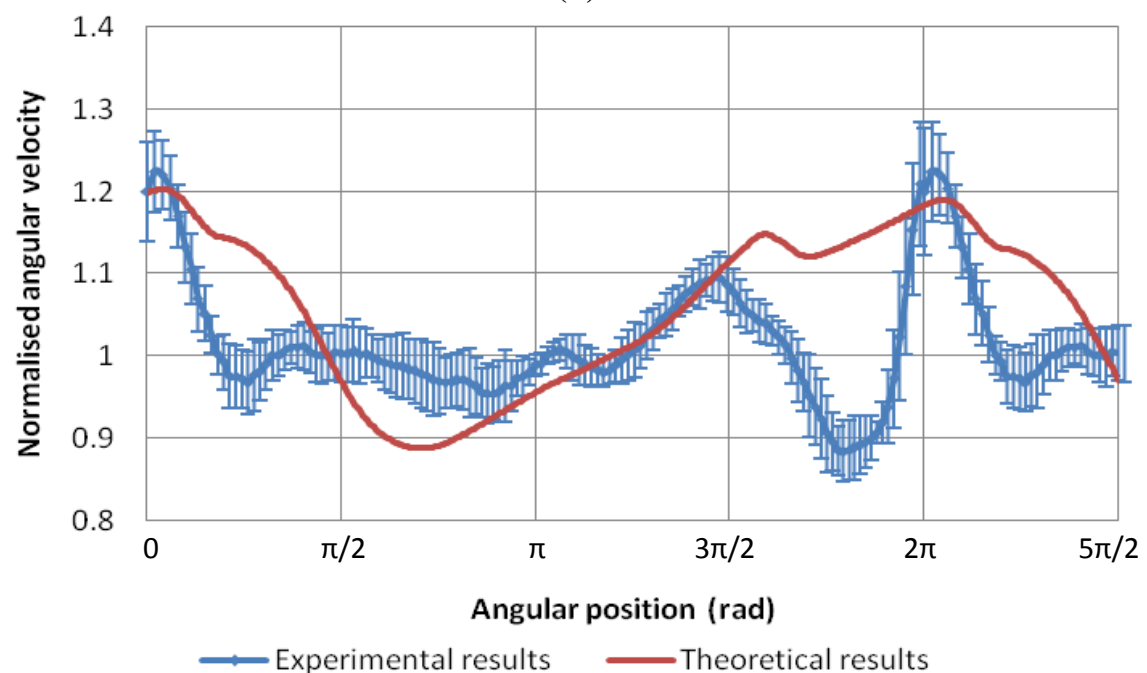

(c)

Fig. 6 Comparison between the experimental and theoretical variations in angular velocity with angular position ( $(\theta)$ during one oscillation at $16 \mathrm{dm}^{3} / \mathrm{h}$ in a water flow: (a) PMMA piston; (b) carbon piston; (c) 316 SS piston with low-friction coating. 


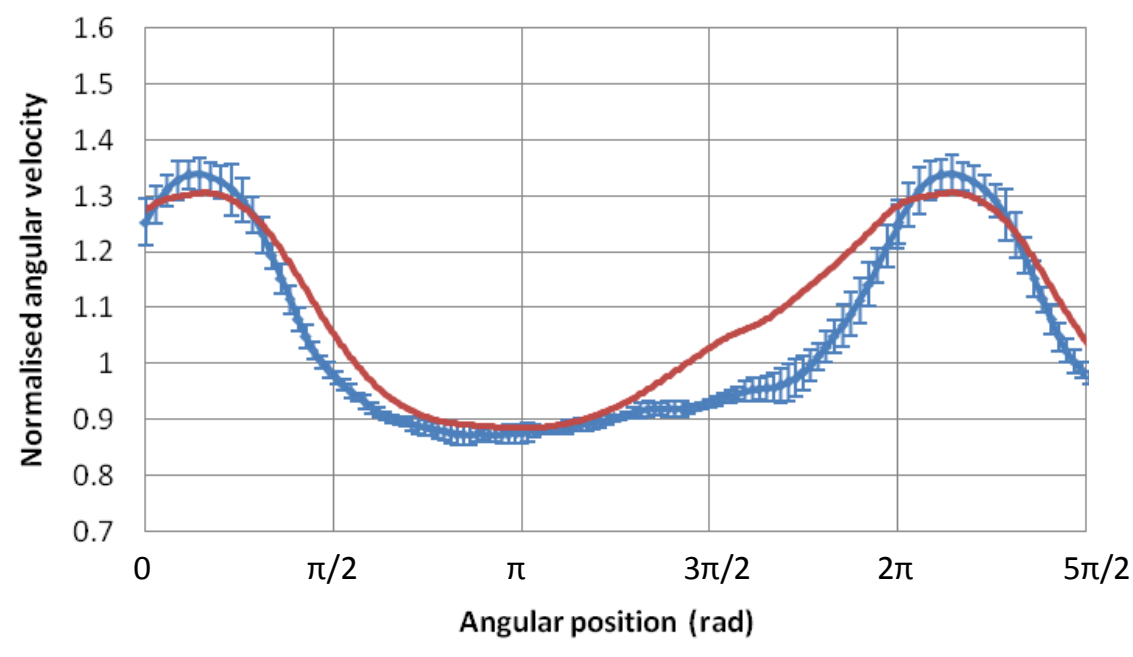

$\longrightarrow$ Experimental results Theoretical results

(a)

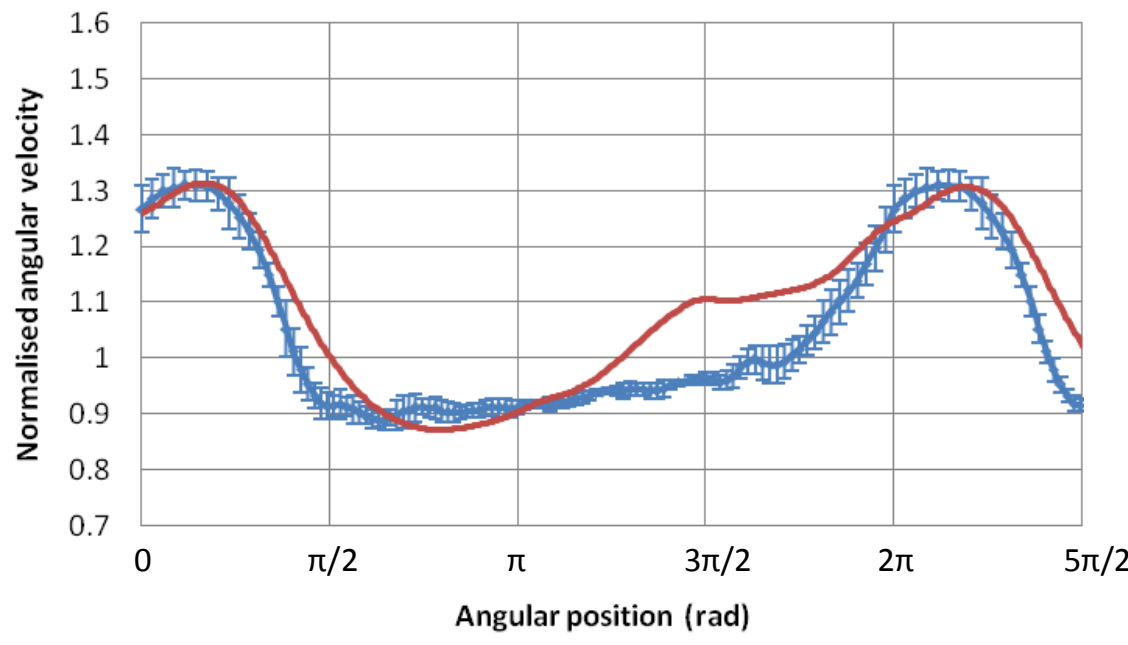

$\longrightarrow$ Experimental results $\quad$ Theoretical results

(b)

Fig. 7 Comparison between the experimental and theoretical variations in angular velocity with angular position $(\theta)$ during one oscillation at $80 \mathrm{dm}^{3} / \mathrm{h}$ with the $316 \mathrm{SS}$ piston in a water flow: (a) with lowfriction coating; (b) no coating.

Figs. 7 and 8 show the variation in angular velocity for the coated and uncoated 316 SS pistons at $80 \mathrm{dm}^{3} / \mathrm{h}$ and $32 \mathrm{dm}^{3} / \mathrm{h}$ respectively. The theoretical range of angular velocity in both cases was in agreement with experiments. However, a difference is apparent over the range between $\theta=\pi$ and $\theta=2 \pi$.

At lower flow rates, the range of angular velocities obtained theoretically was in agreement with those obtained experimentally. However, again there was a discrepancy in the range 
between $\theta=3 \pi / 2$ and $\theta=2 \pi$. The results for the uncoated piston showed better agreement, although the model does not predict the possible 'slip-stick' motion observed experimentally.

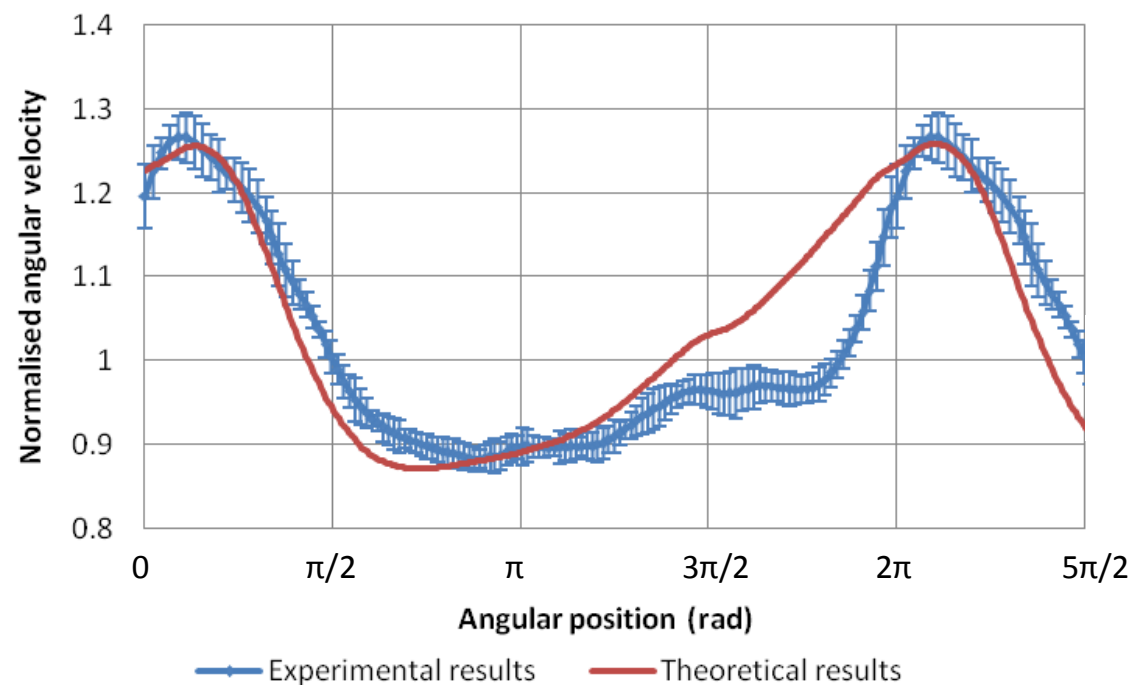

(a)

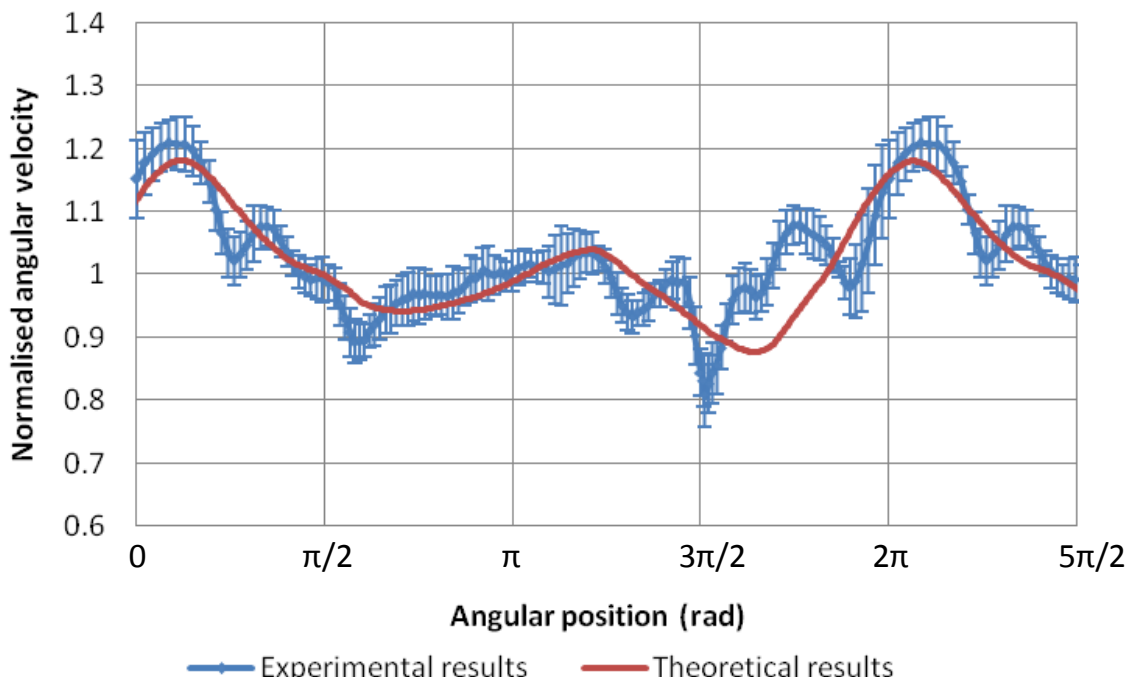

(b)

Fig. 8 Comparison between the experimental and theoretical variations in angular velocity with angular position $(\theta)$ during one oscillation at $32 \mathrm{dm}^{3} / \mathrm{h}$ with the $316 \mathrm{SS}$ piston in a water flow: (a) with lowfriction coating; (b) no coating.

The model predictions for the effects of lubrication holes and slots in the skirt were generally in similar agreement as for Fig. 4(a), with similar discrepancies between $\theta=\pi / 2$ and $\theta=\pi$ and between $\theta=3 \pi / 2$ and $\theta=2 \pi$. The model predicts that with the slots in the piston skirt 
wall, there is a larger variation in the angular velocity than without the slots, in agreement with experiment.

For changes in up- and downstream pipework length the agreement is good and similar to Fig. 4(a) for the $20 \mathrm{~m}$ pipe length, except that the prediction was slightly below the experimental curve between $\theta=3 \pi / 2$ and $\theta=2 \pi$. As the combined length of up- and downstream pipework increased the model predicted that the angular velocity variation increased, as was found experimentally. For the $0.2 \mathrm{~m}$ length the range of angular velocities was about half that for $20 \mathrm{~m}$.

\subsection{Effect of meter size change using the VFF4 and the LF15}

Comparisons between the experimental and theoretical angular velocities for the VFF4, the MF30 and the LF15 meters (see Table 2) are given in Figs. 4(a) \& 9 for an average frequency of $5 \mathrm{~Hz}$, corresponding to flow rates of $210 \mathrm{dm}^{3} / \mathrm{h}, 80 \mathrm{dm}^{3} / \mathrm{h}$ and $35 \mathrm{dm}^{3} / \mathrm{h}$ respectively.

It is evident that the variation in angular velocity does not differ greatly between the different sized meters. There was a slightly larger variation for the LF15 than the VFF4 but the general shape of the curve remained the same. As with the MF30, the range of angular velocities and positions for maximum and minimum angular velocity were in excellent agreement with the model. The discrepancies just before TDC are also apparent for these meters. 


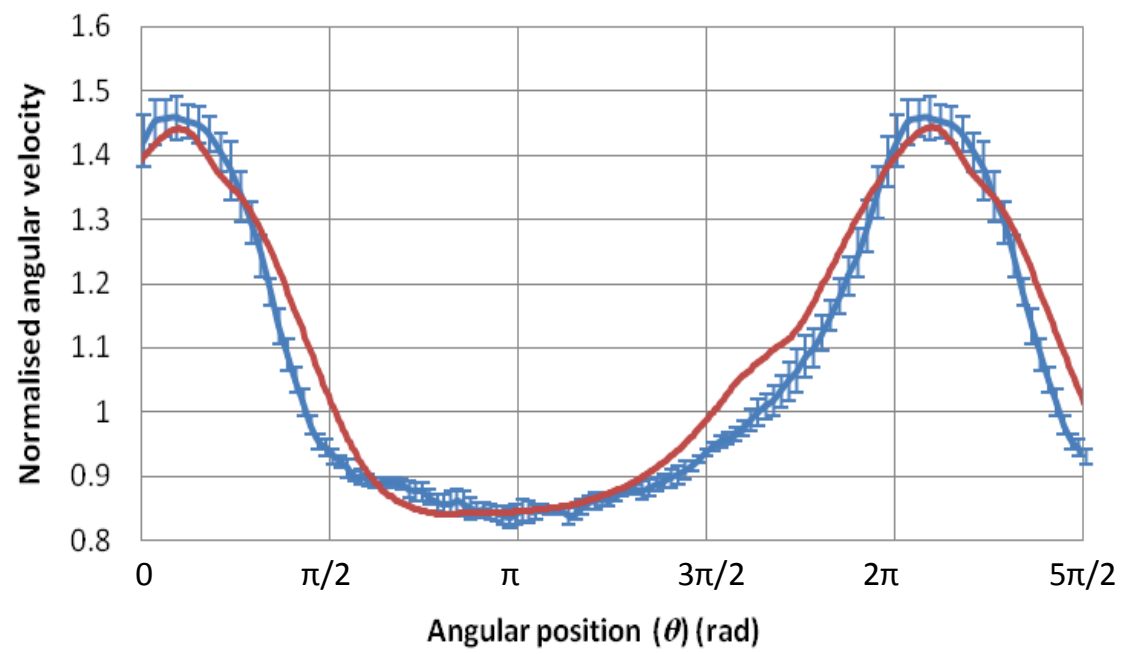

(a)

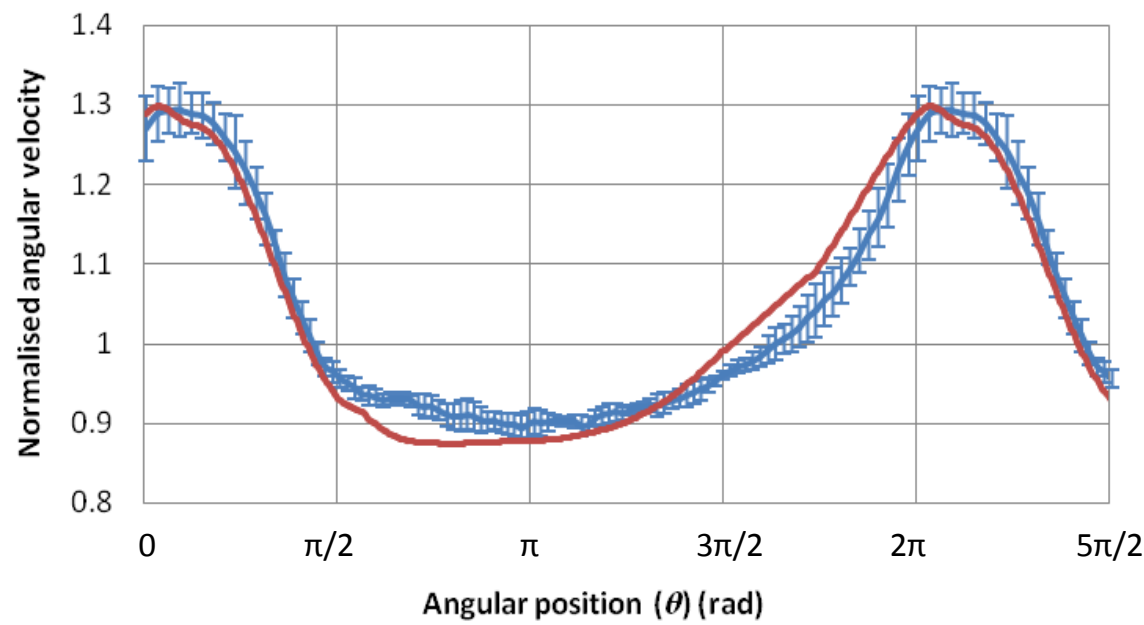

Experimental results Theoretical results

(b)

Fig 9 Comparison between the experimental and theoretical angular velocity variations with angular position $(\theta)$ for the carbon piston at an average rotation/oscillation frequency of $5 \mathrm{~Hz}$ in a water flow: (a) LF15; (b) VFF4.

\subsection{Measurement of motion in the vertical direction}

Experiments to measure the vertical movement were reported by Morton et al [4]. Results obtained from the theoretical model included minimum, mean and maximum clearance between the bottom of the piston and the measuring chamber, the angular tilt and the angle through which the maximum tilt acts. Fig. 10 shows both the experimental and theoretical results for the full movement of the carbon piston in the vertical direction. The clearance was that between the bottom of the piston and measuring chamber. 
The results obtained from the model were in good agreement with those found experimentally, particularly with the minimum, mean and maximum clearances and fell within the uncertainty limits of the experimental results. The model did, however, predict that just before TDC, there was no tilting, although in practice the piston tilted throughout the entire rotation. The angle through which the maximum tilt acted is given in Fig. 10(c). Again this shows good agreement with the experimental results. 


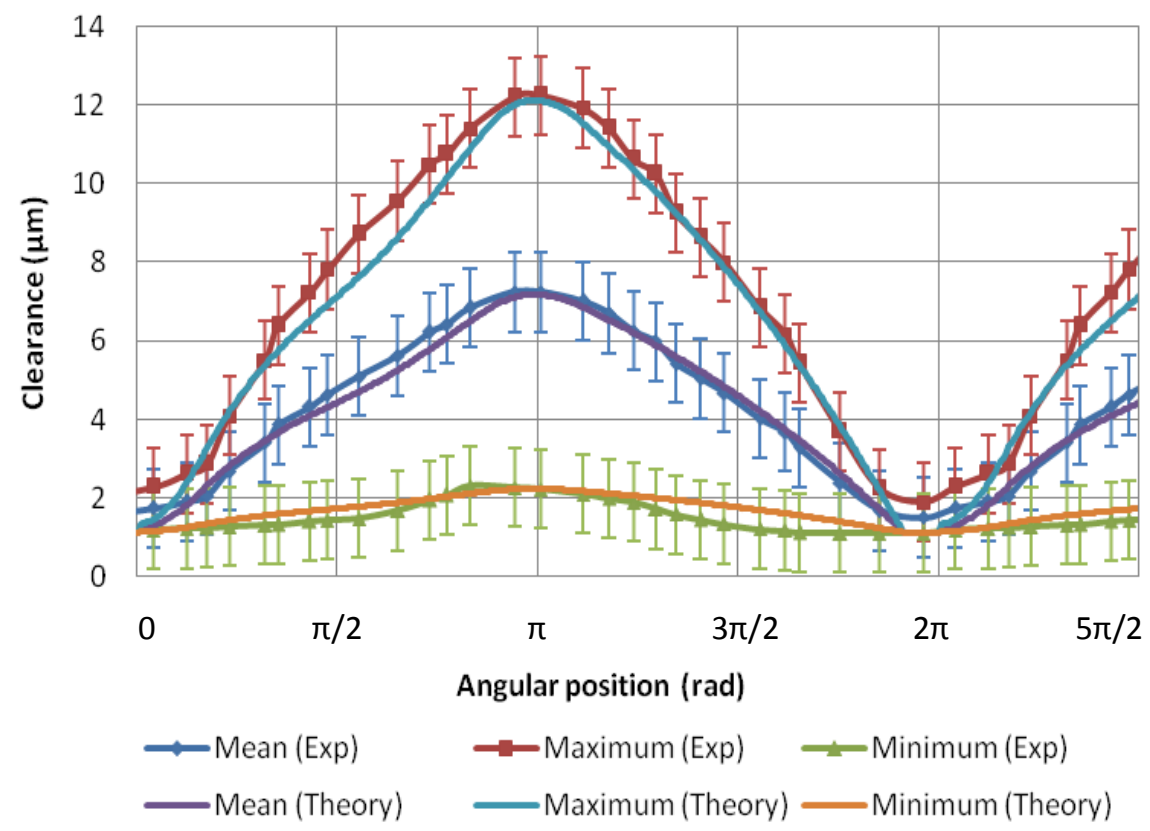

(a)

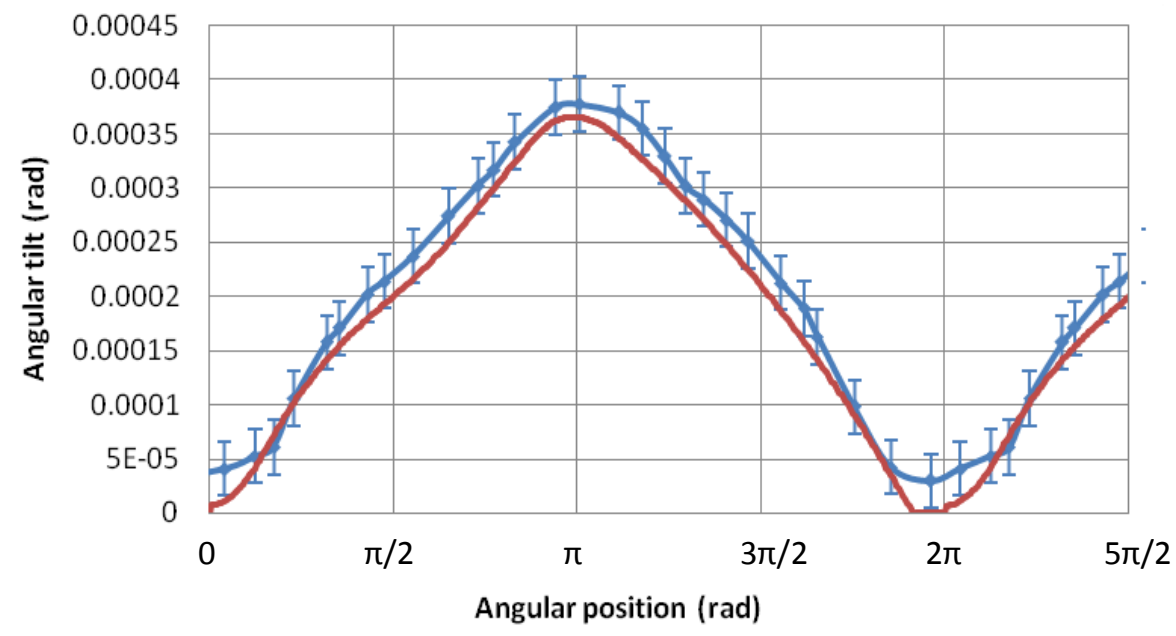

$\longrightarrow$ Experimental results $\longrightarrow$ Theoretical results

(b)

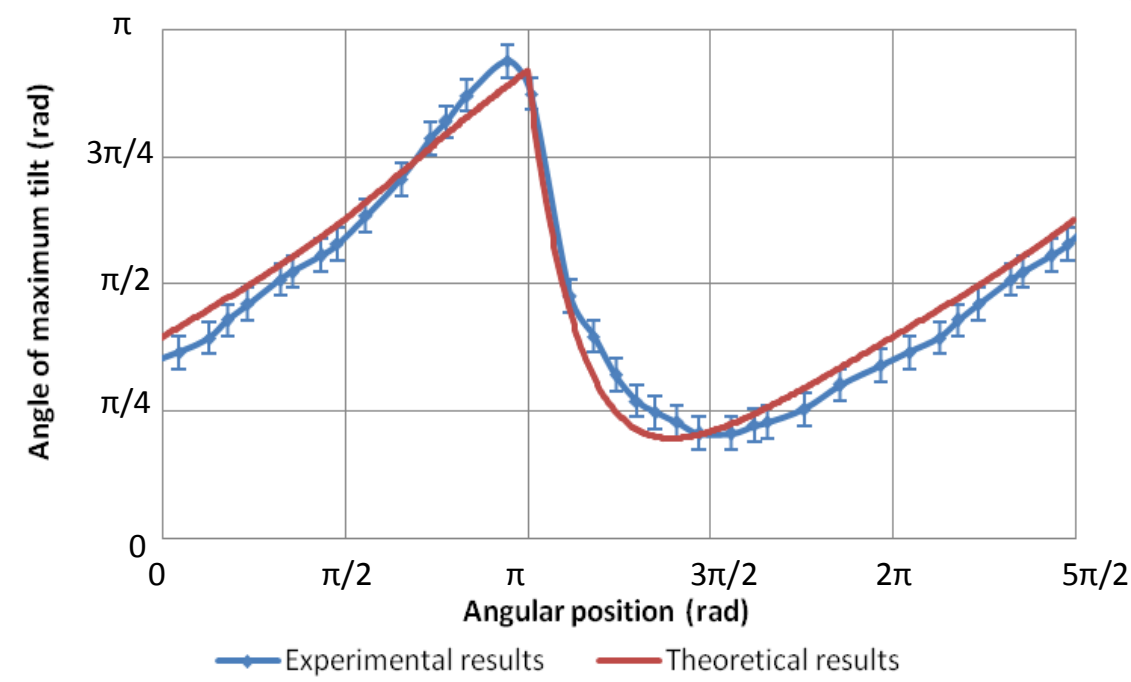

(c) 
Fig 10 Comparison between the experimental and theoretical results for variation with angular position

( $\theta$ ) for the carbon piston at $80 \mathrm{dm}^{3} / \mathrm{h}$ in a water flow: (a) minimum, mean and maximum clearances; (b) angular tilt; (c) angle through which maximum tilt acts. 


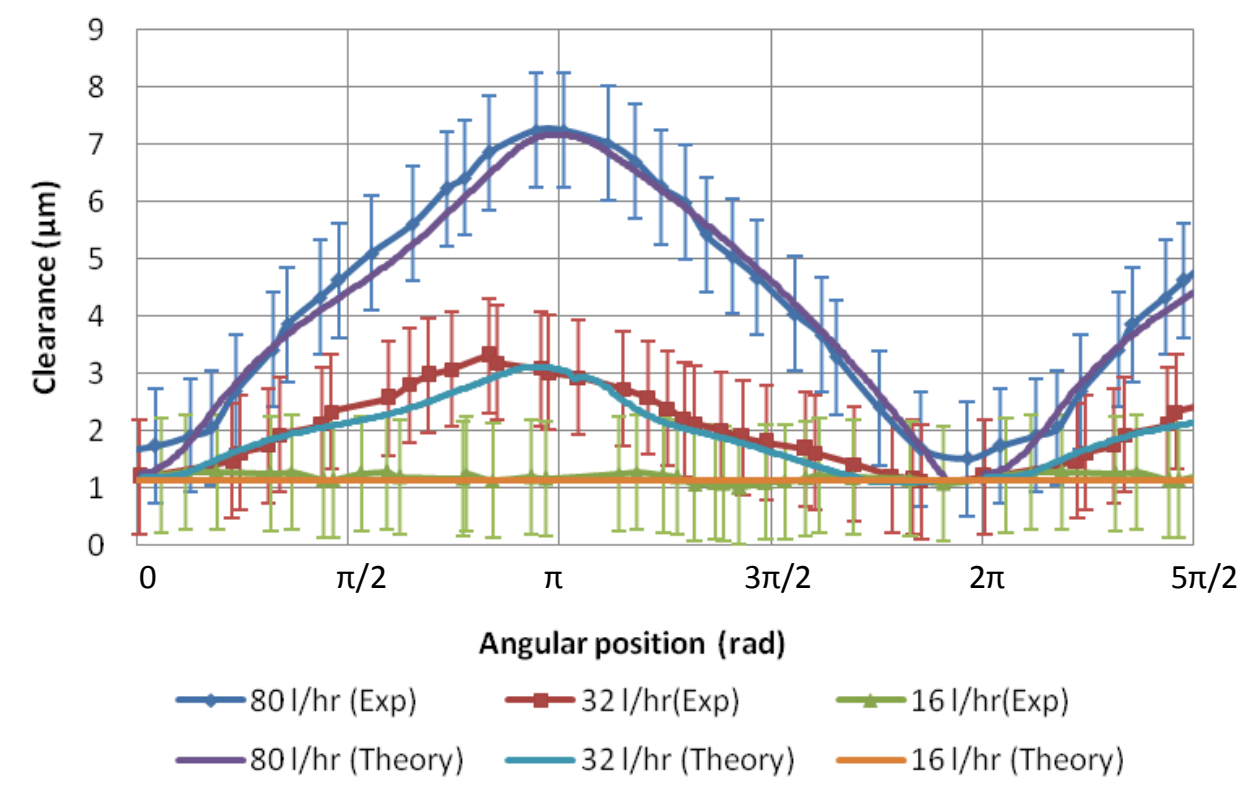

(a)

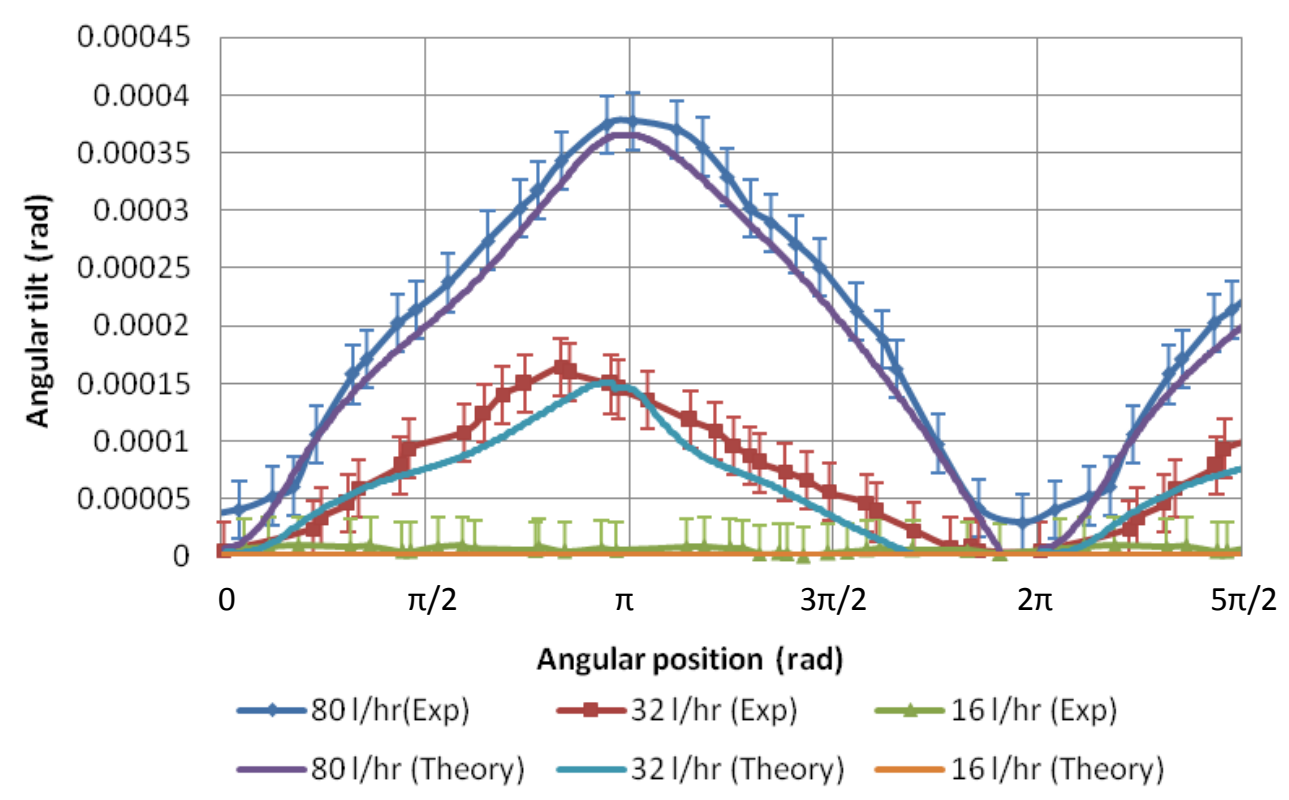

(b)

Fig. 11 Comparison between the experimental and theoretical results for the carbon piston at different flow rates in a water flow for variation with angular position ( $\theta)$ of: (a) mean clearances; (b) angular tilt.

The mean clearance and angular tilt are given for the carbon piston at $80 \mathrm{dm} / \mathrm{h}, 32 \mathrm{dm}^{3} / \mathrm{h}$ and $16 \mathrm{dm}^{3} / \mathrm{h}$ in Fig. 11. The experimental and theoretical results were, again, in good agreement and the theoretical results fell within the $95 \%$ confidence level of the experimental results. The model correctly predicted that at lower flow rates $\left(16 \mathrm{dm}^{3} / \mathrm{h}\right)$ the bottom of the piston did not lift off the bottom of the measuring chamber. 


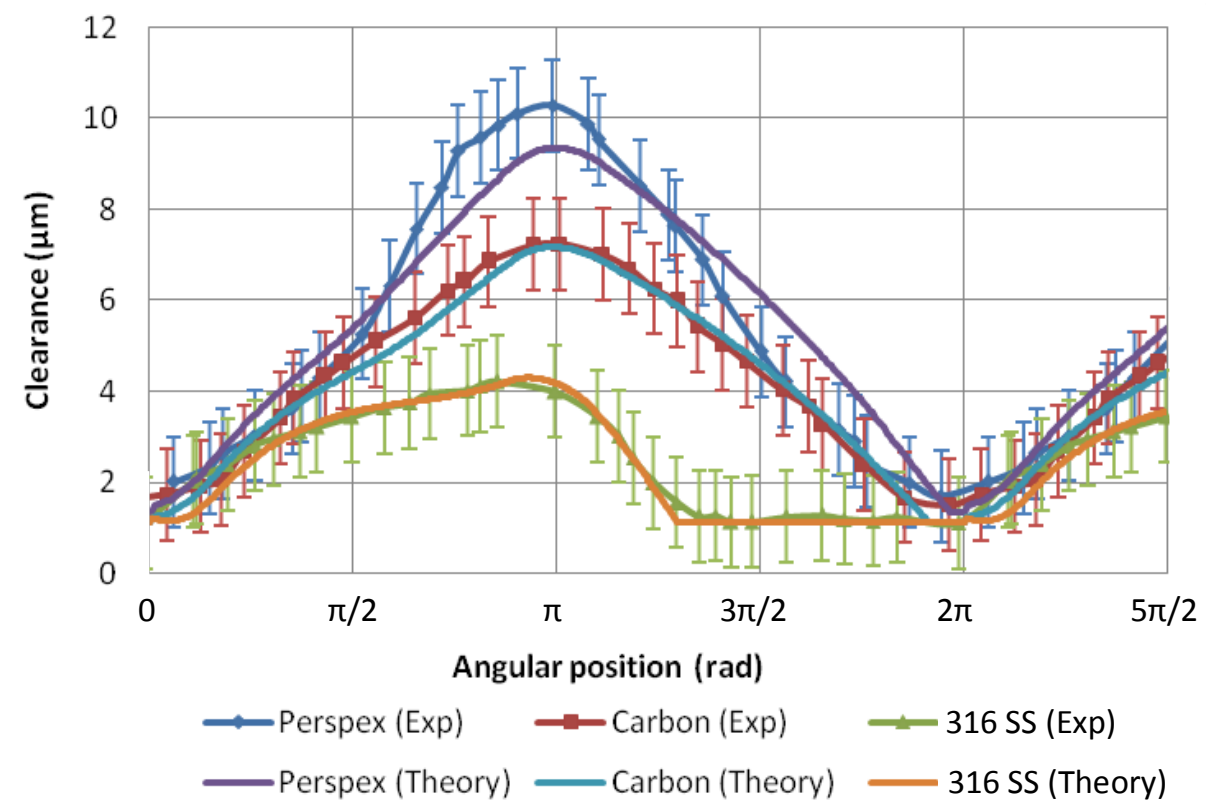

(a)

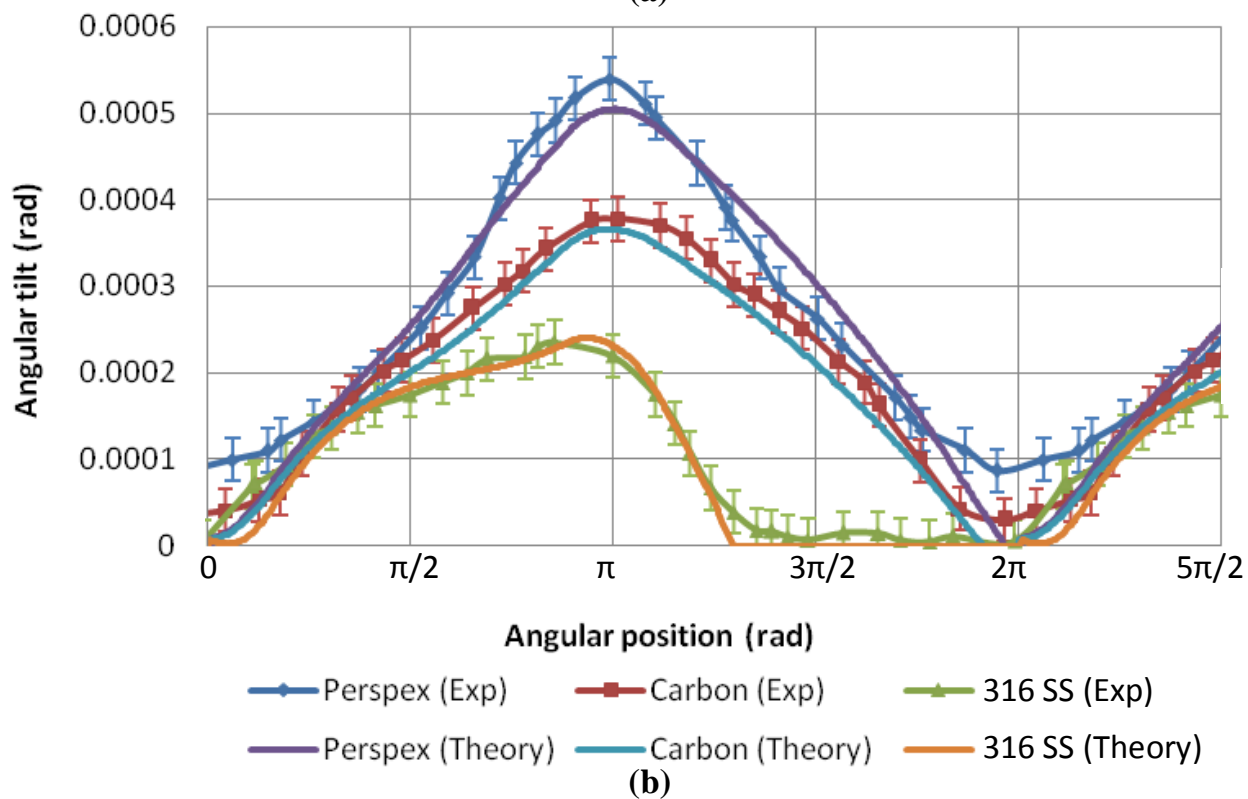

Fig. 12 Comparison between the experimental and theoretical results for different mass pistons at 80 $\mathrm{dm}^{3} / \mathrm{h}$ in a water flow for variation with angular position $(\theta)$ of: (a) mean clearances; (b) angular tilt.

Fig. 12 shows the experimental and theoretical results for the different mass pistons at 80 $\mathrm{dm}^{3} / \mathrm{h}$. The model showed good agreement for both the $316 \mathrm{SS}$ and carbon pistons, within the uncertainty of the experimental results. With the lighter PMMA piston, the agreement was less good, although for much of the rotation, the theoretical results did fall within the uncertainty limits. At lower flow rate $\left(16 \mathrm{dm}^{3} / \mathrm{h}\right)$, the model predicted that neither the $316 \mathrm{SS}$ nor carbon pistons would lift off from the bottom of the measuring chamber, in agreement 
with the experiments. The PMMA piston did lift off, and the results from the model were within the uncertainty of the experimental results. At this flow rate the movement in the vertical direction was very small for all pistons.

The model predicted that with no lubrication holes, there was more movement in the vertical direction, in agreement with the results found experimentally. At lower flow rate $\left(16 \mathrm{dm}^{3} / \mathrm{h}\right)$, if the lubrication holes were open, the piston would not lift off from the bottom of the measuring chamber. With the lubrication holes closed there was lift-off and the results from the model fell within the uncertainty of the experimental results. 


\subsection{Pressure losses across the meter}

Fig. 13(a) shows the time-average pressure losses across the full flow range for a carbon piston in a water flow (see [3] for pressure measurement information). Figs. 13(b) and (c) show the time-varying pressure losses at $80 \mathrm{dm}^{3} / \mathrm{h}$ and $16 \mathrm{dm}^{3} / \mathrm{h}$. The agreement between the experimental and theoretical results for the average pressure losses was good, and within the uncertainty limits of the experimental results. The agreement between the detailed pressure losses at both $80 \mathrm{dm}^{3} / \mathrm{h}$ and $16 \mathrm{dm}^{3} / \mathrm{h}$ was also good. Both the range of pressure losses and the positions for maximum and minimum were in agreement. At $80 \mathrm{dm}^{3} / \mathrm{h}$ there were small discrepancies just before and after TDC, although for most of the rotation/oscillation, the results lie within the experimental uncertainty. At $16 \mathrm{dm}^{3} / \mathrm{h}$ there were again small discrepancies just after TDC, and also just after BDC, although all the predictions lay within the uncertainty range of the experimental data.

Fig. 14 shows the pressure losses for the 316 SS piston against flow rate and as a time average. The theoretical losses were slightly higher than those found experimentally and at 90 $\mathrm{dm}^{3} / \mathrm{h}$ fell just outside the uncertainty limits. The pressure losses for the PMMA piston showed a similar level of agreement to those for the carbon piston. Fig. 15 shows the detailed pressure losses for the PMMA, carbon and $316 \mathrm{SS}$ pistons at $16 \mathrm{dm}^{3} / \mathrm{h}$.

Generally, the agreement between the experimental and theoretical results was good, but as the piston mass increased, the agreement was less good. At $80 \mathrm{dm}^{3} / \mathrm{h}$ there were small discrepancies just before and after TDC. 


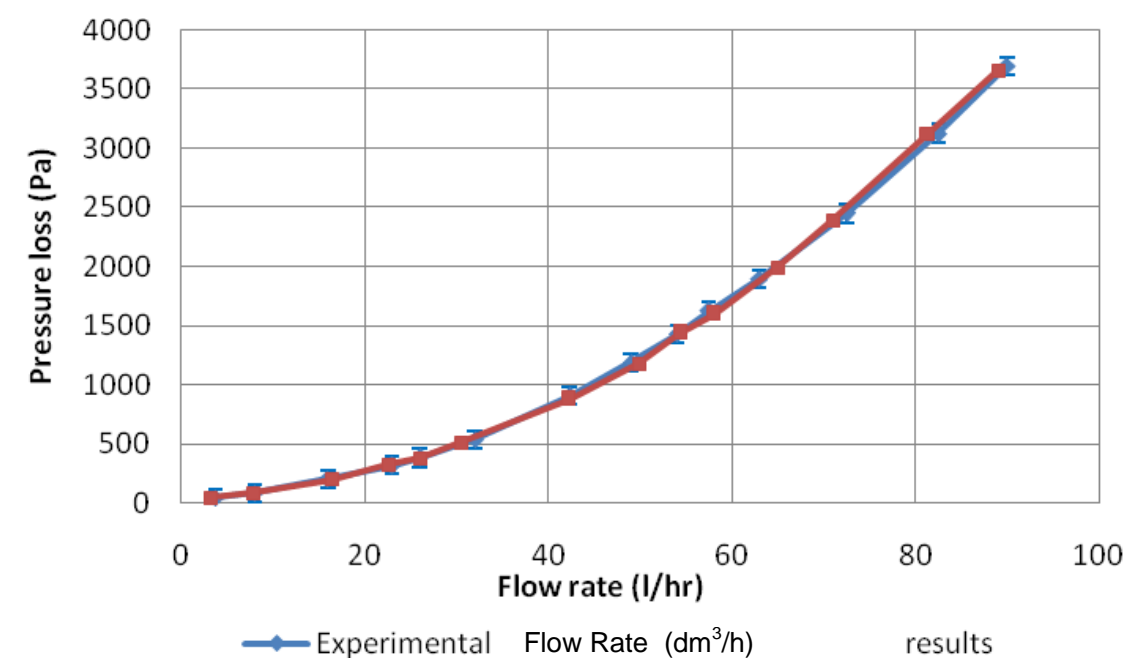

(a)

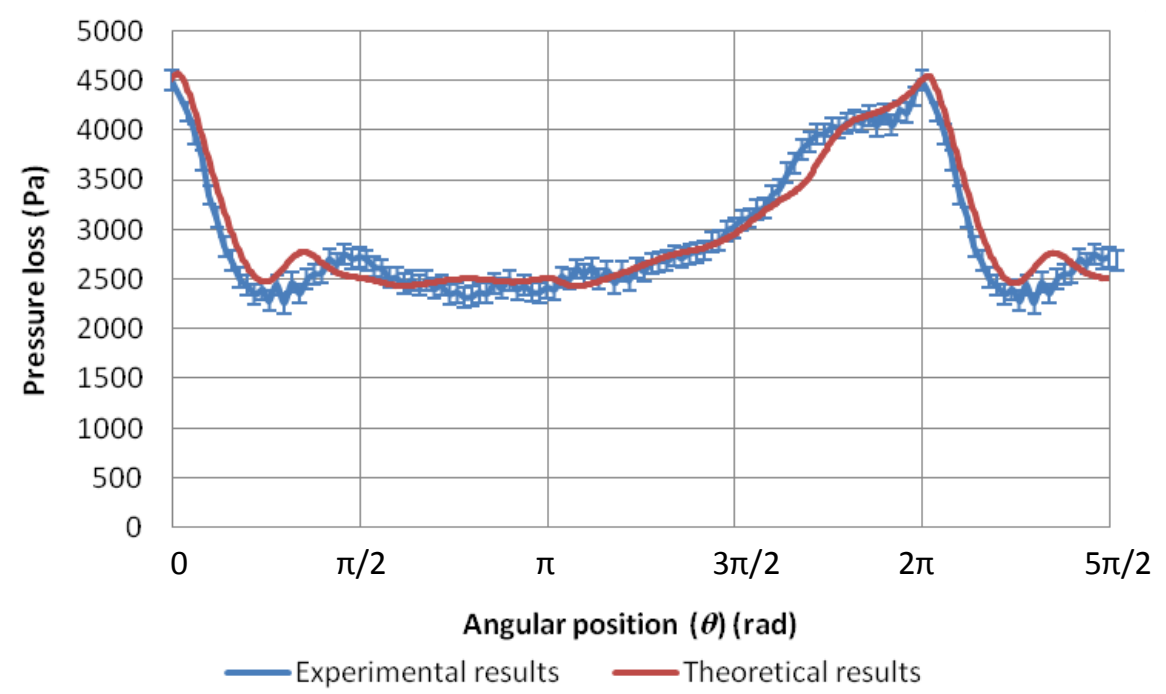

(b)

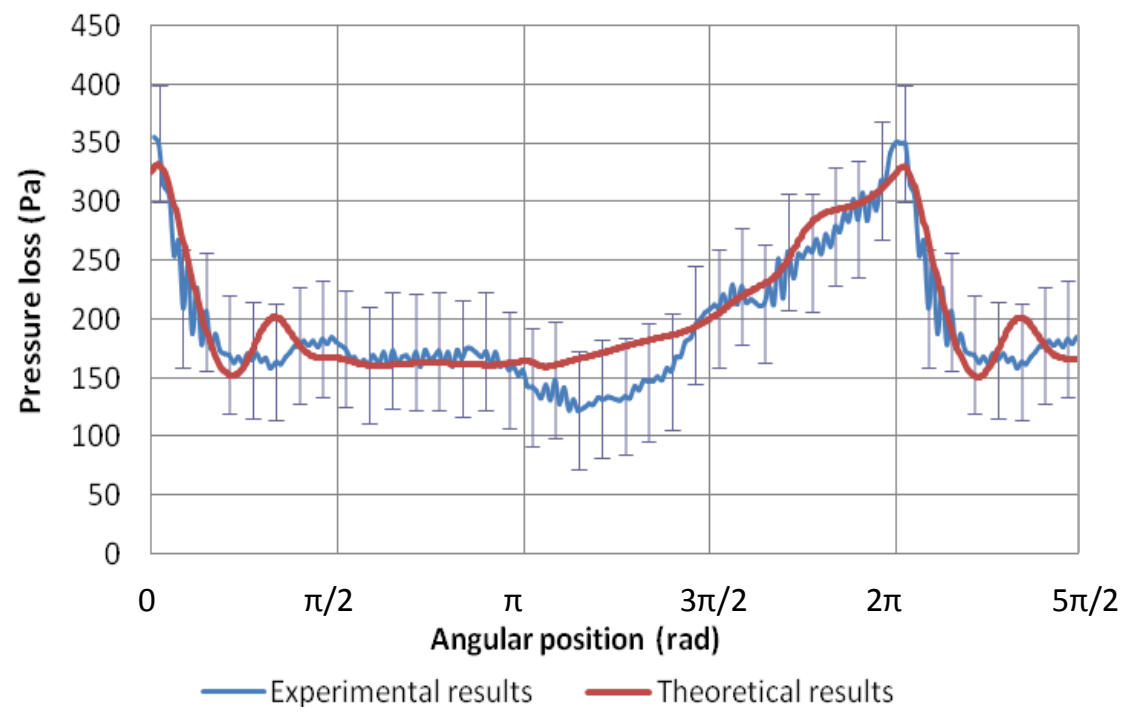

(c)

Fig. 13 Comparison between the experimental and theoretical pressure losses for the carbon piston in a water flow for variation with angular position $(\theta)$ of pressure loss: (a) with flow rate; (b) at $80 \mathrm{dm}^{3} / \mathrm{h}$; (c) at $16 \mathrm{dm}^{3} / \mathrm{h}$. 


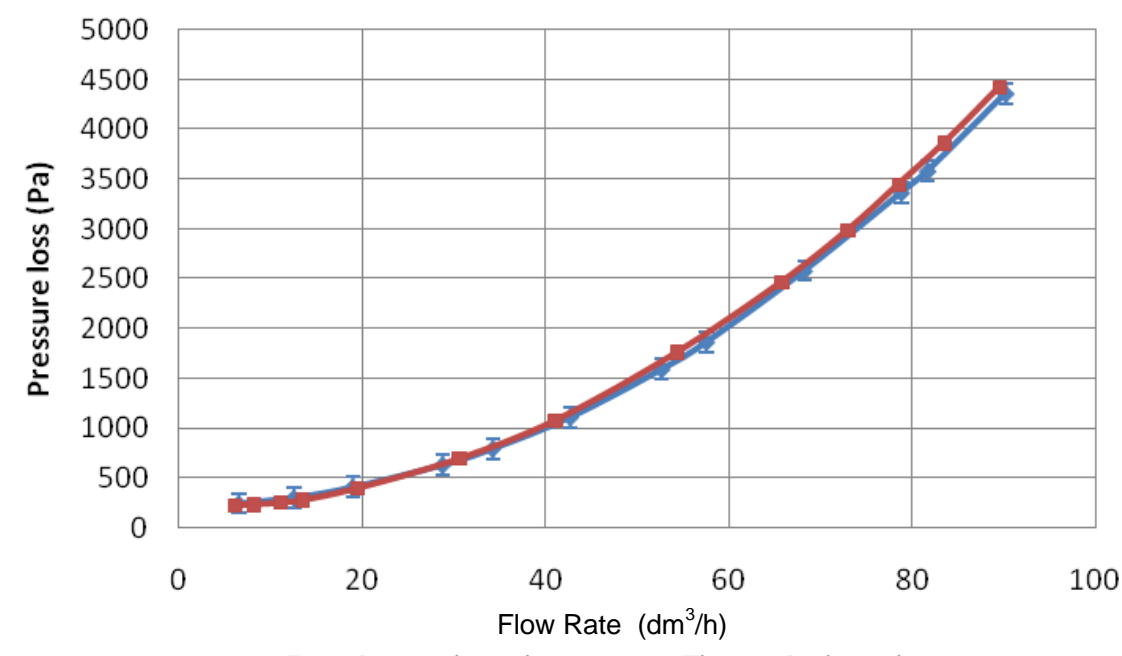

Experimental results $\quad-$ Theoretical results

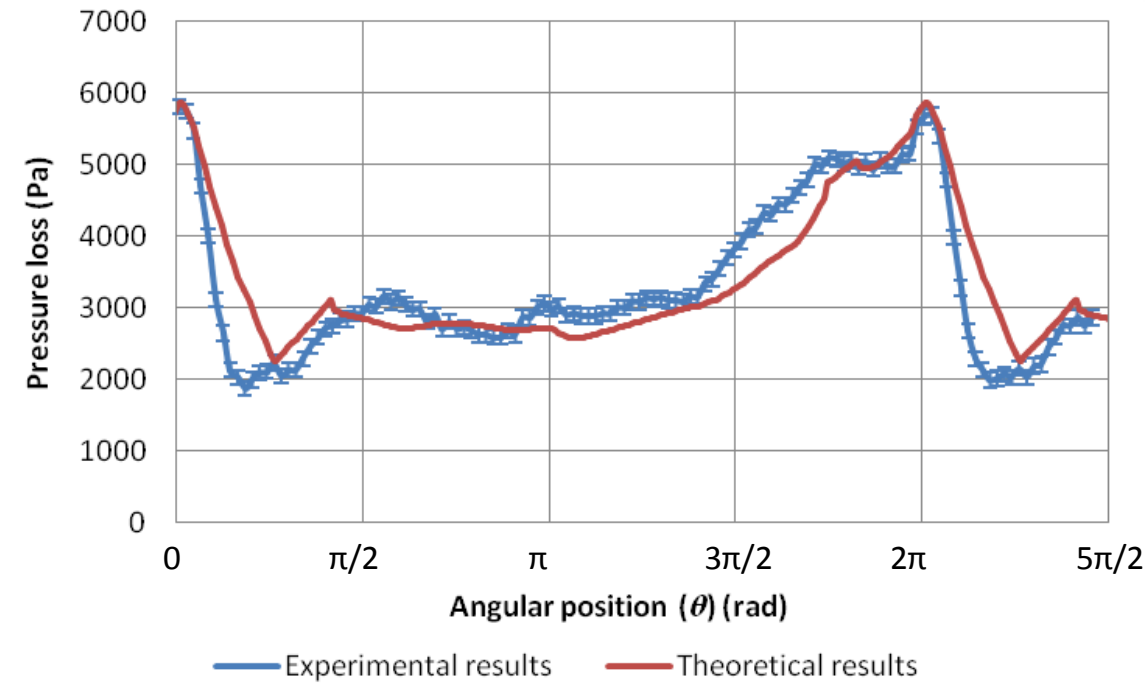

(b)

Fig. 14 Comparison between the theoretical and experimental results for the 316 SS piston with low-

friction coating in a water flow for variation with angular position $(\theta)$ of pressure loss: (a) with flow rate; (b) at $80 \mathrm{dm}^{3} / \mathrm{h}$ 

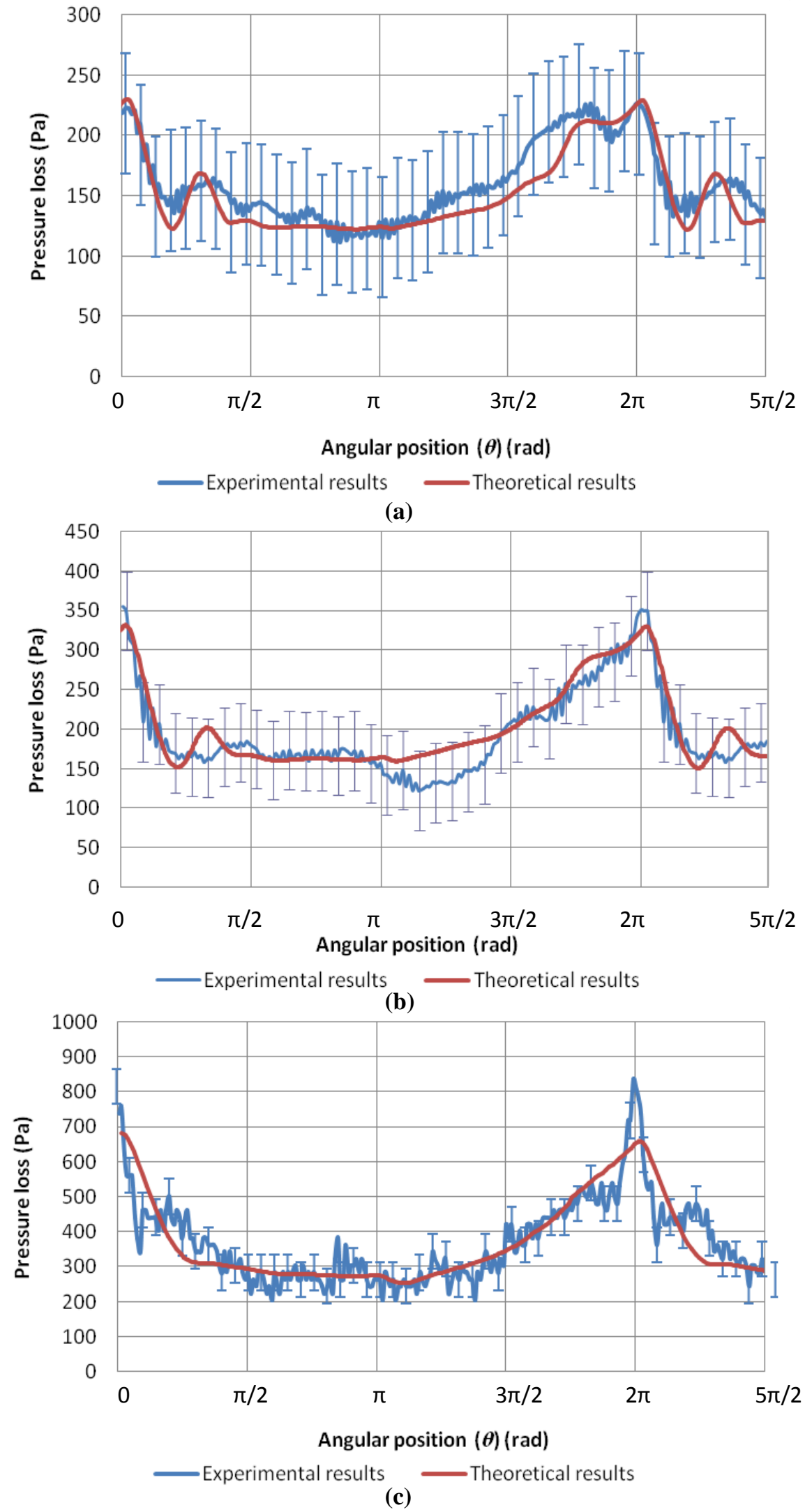

Fig. 15 Comparison between the experimental and theoretical variation of pressure losses with angular

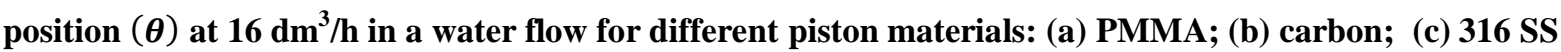
with low-friction coating. 
Agreement between the theoretical and experimental average pressure loss with flow rate for the 316 SS piston with and without coating was similar to that in Fig. 14(a). With the coating the losses were typically $2 \%$ higher than those found experimentally, and without the coating the losses were typically $4 \%$ higher than those found experimentally.

Fig. 16 shows the detailed pressure losses for the $316 \mathrm{SS}$ piston at $80 \mathrm{dm}^{3} / \mathrm{h}$ with and without the Molykote coating, and Fig. 17 at $16 \mathrm{dm}^{3} / \mathrm{h}$. While the general agreement was satisfactory, the model did not predict the smaller-scale variations obtained experimentally with no coating. There were discrepancies both with and without the coating but the shape of the curve found theoretically did agree with the shape found experimentally 


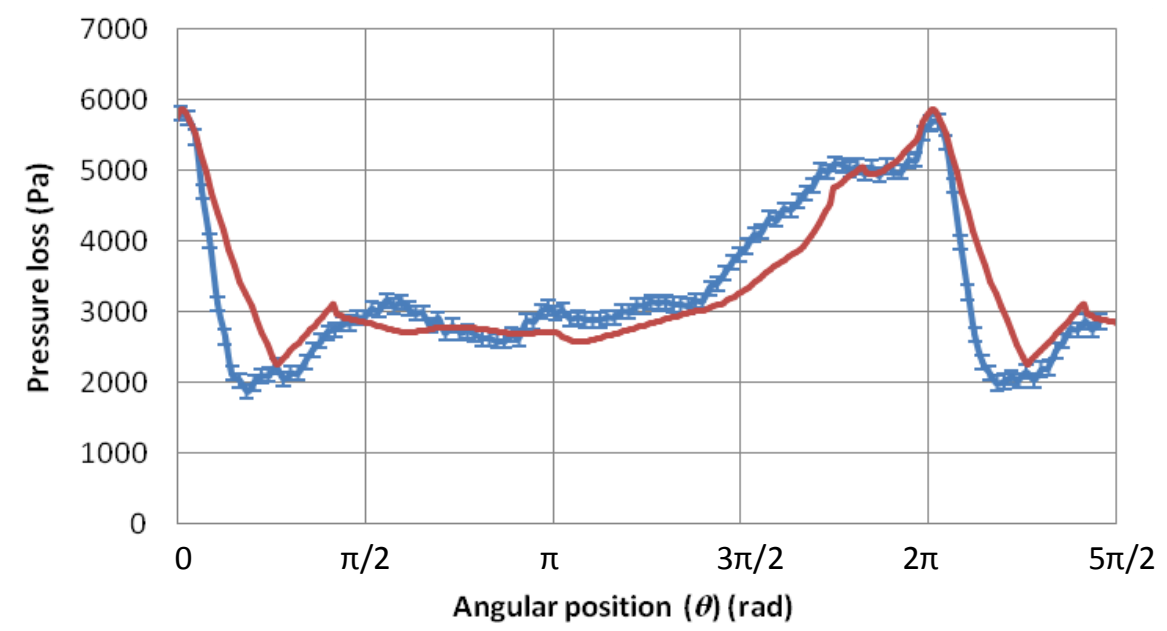

Experimental results $\quad$ Theoretical results

(a)

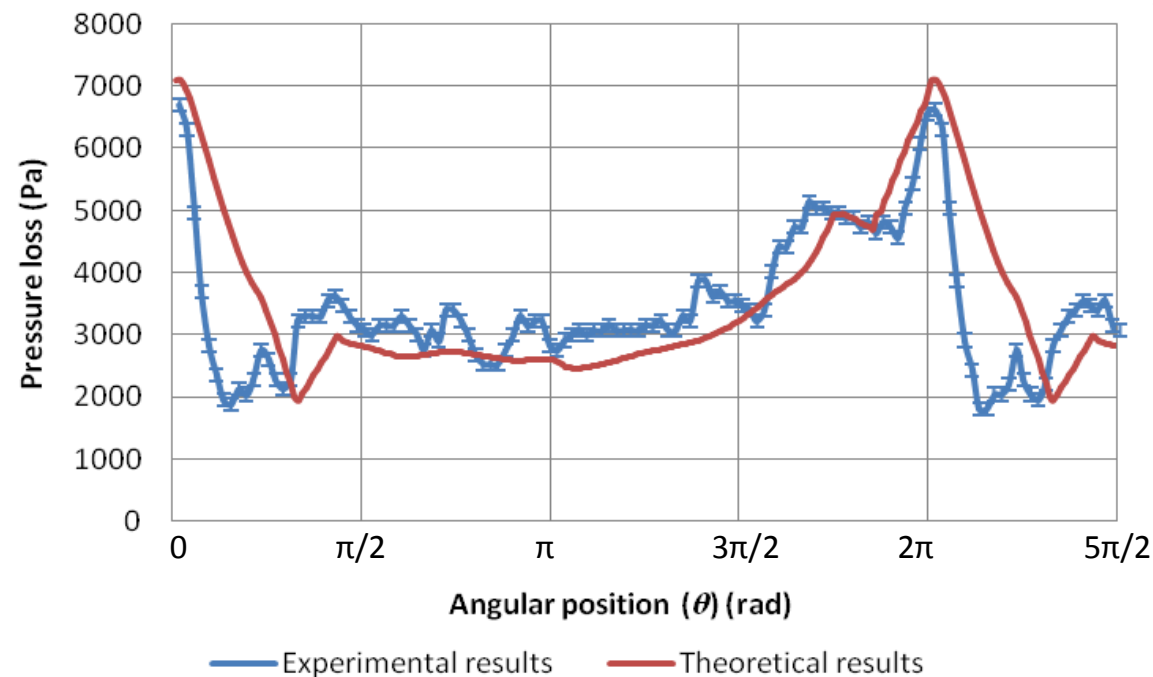

(b)

Fig. 16 Comparison between the experimental and theoretical variation of pressure losses with angular position ( $\theta$ ) in a water flow at $80 \mathrm{dm}^{3} / \mathrm{h}$ for a $316 \mathrm{SS}$ pistom: (a) with low-friction coating ; (b) uncoated piston. 


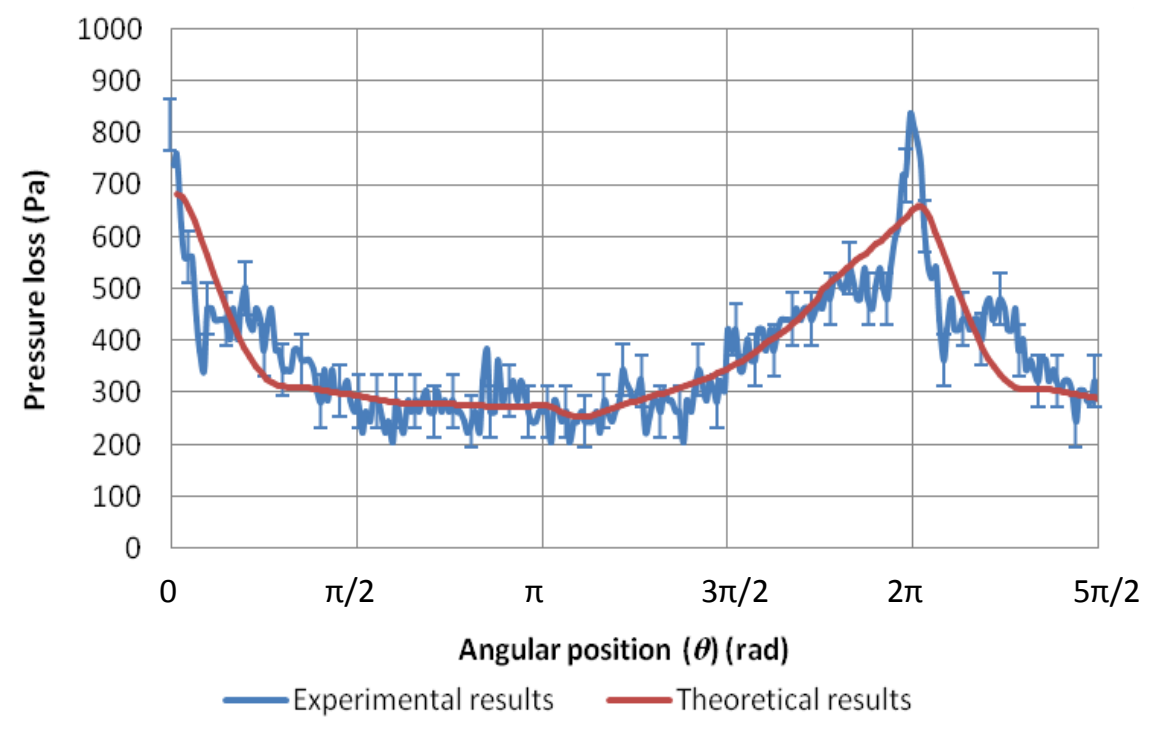

(a)

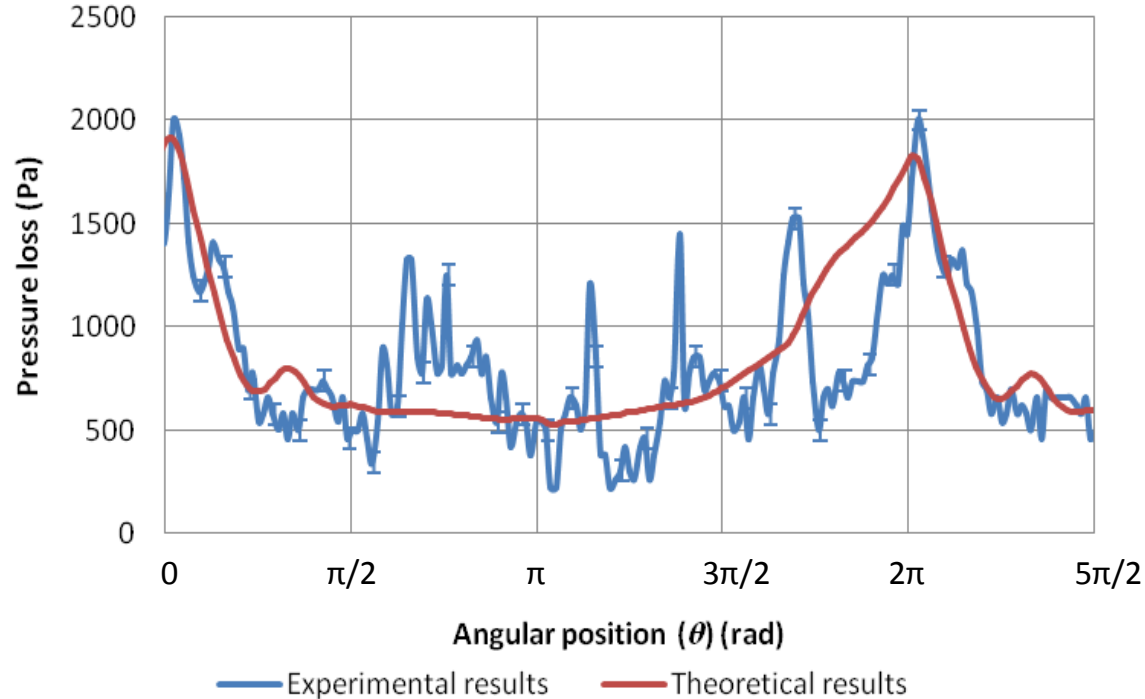

(b)

Fig. 17 Comparison between the experimental and theoretical variation of pressure losses with angular position $(\theta)$ in a water flow at $16 \mathrm{dm}^{3} / \mathrm{h}$ : (a) with low-friction coating ; (b) uncoated piston. 


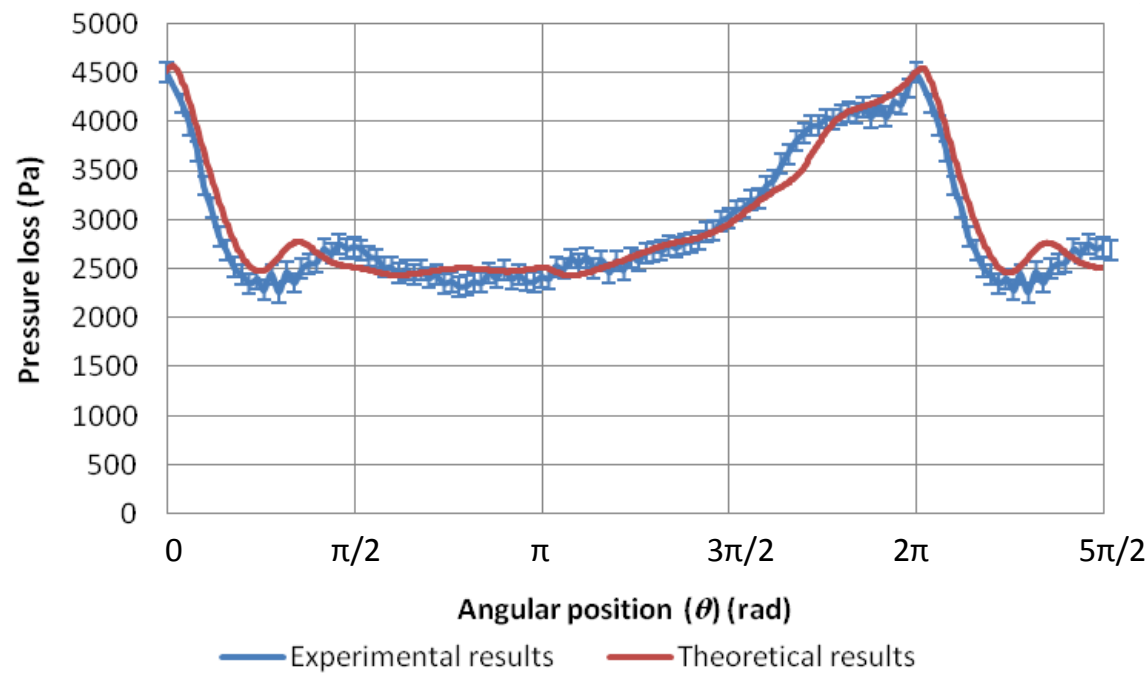

(a)

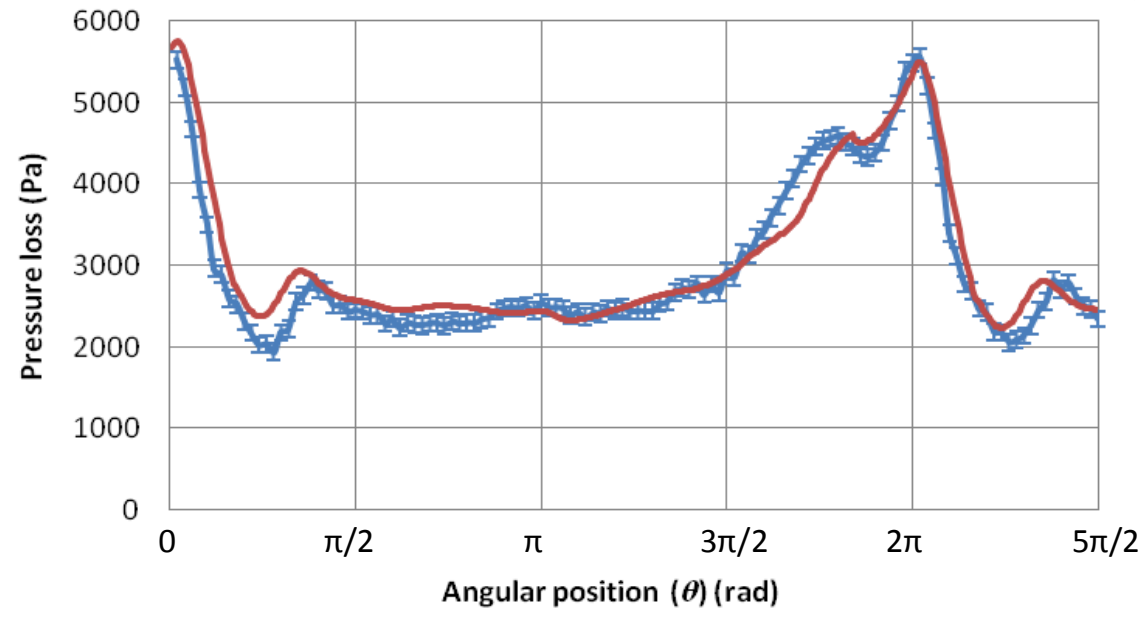

(b)

Figure 18 Comparison between the experimental and theoretical variation of pressure losses with angular position $(\theta)$ in a water flow at $80 \mathrm{dm}^{3} / \mathrm{h}$ : (a) with lubrication holes; (b) no lubrication holes

The average theoretical pressure losses were unaffected by the presence of the lubrication holes, in agreement with the experimental results. The detailed pressure losses with lubrication holes for the carbon piston at $80 \mathrm{dm}^{3} / \mathrm{h}$ are shown in Fig. 18(a) and without the lubrication holes in Fig. 18(b). Experimentally, the pressure losses were found to have greater variation with no lubrication holes, in agreement with the results found theoretically. 


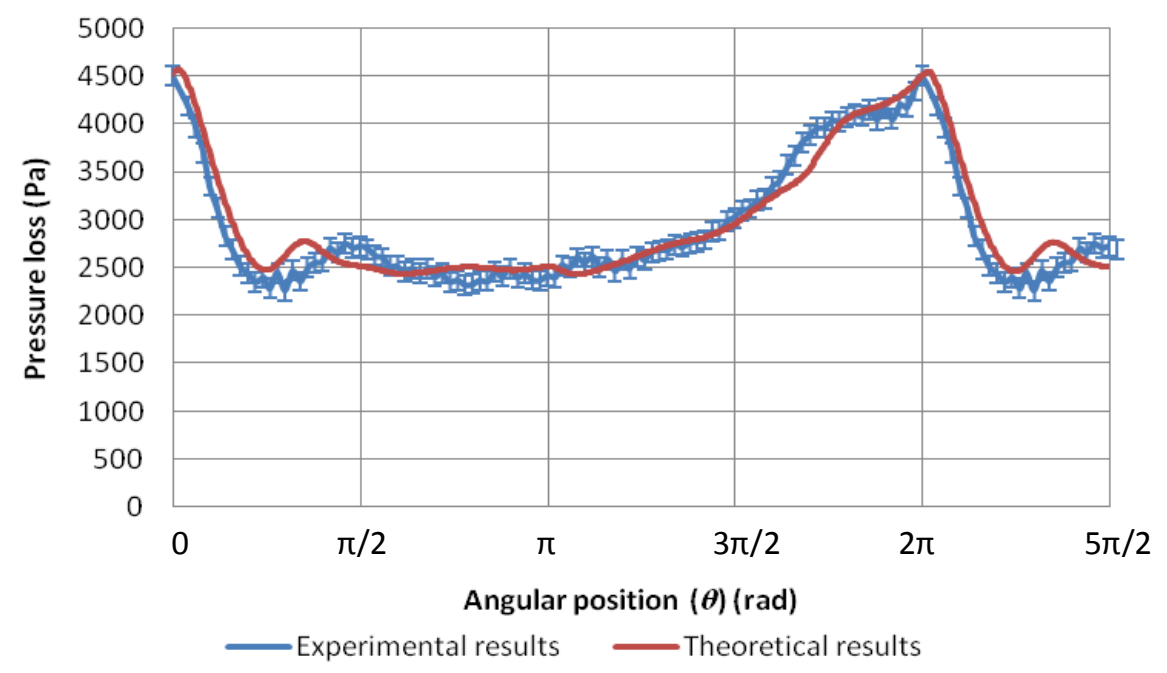

(a)

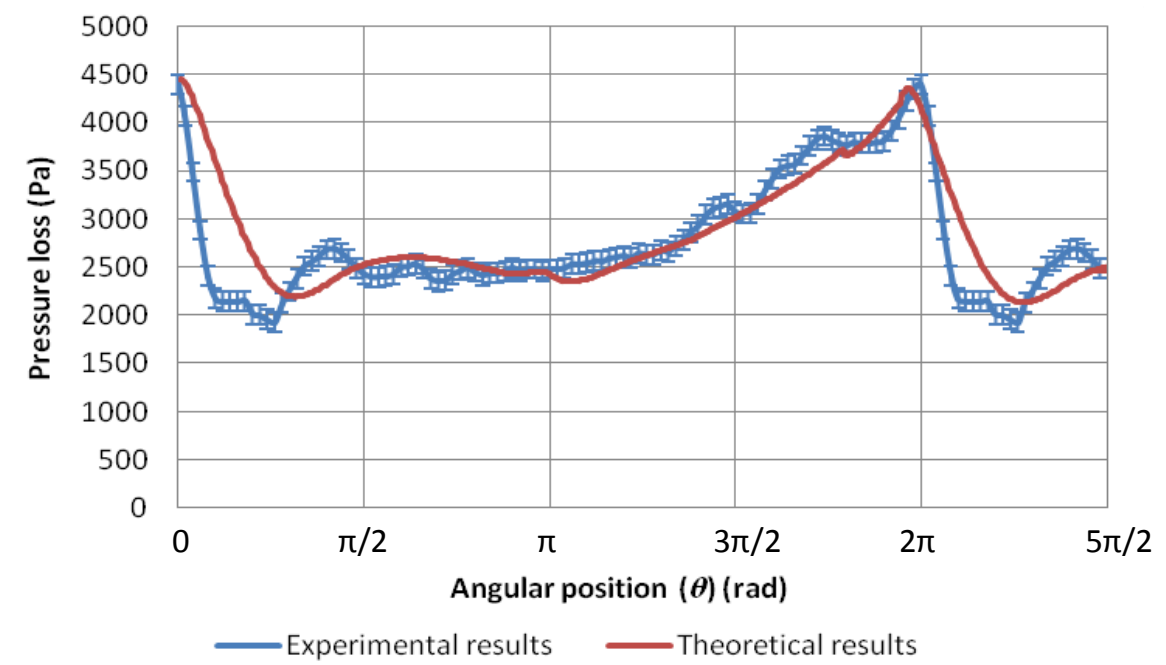

(b)

Figure 19 Comparison between the experimental and theoretical variation of pressure losses with angular position $(\theta)$ for the carbon piston in water at $80 \mathrm{dm}^{3} / \mathrm{h}$ : (a) no slots; (b) with slots

The model prediction for slots in the piston skirt gave a similar level of agreement, Fig. 19 (a)\&(b). However, with the slots in the piston skirt, the theoretical model excluded any effects of trapped liquid, but it is possible that the trapped liquid still had some effect as the liquid entered and left the flowmeter through the slots. 


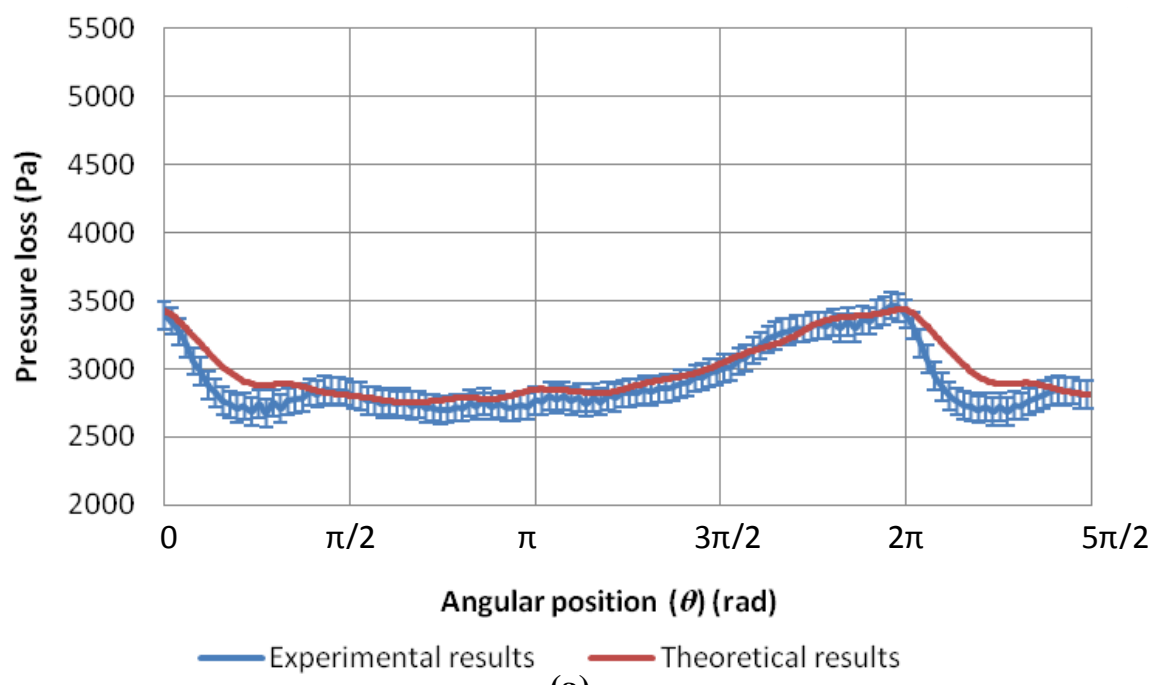

(a)

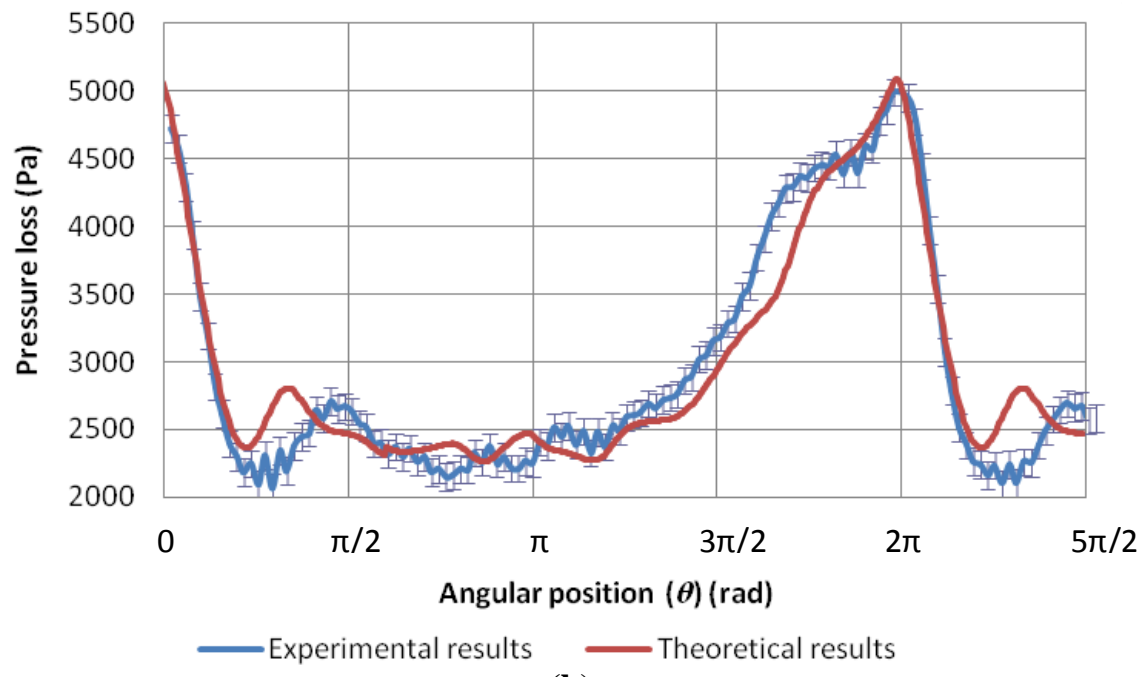

(b)

Fig 20 Comparison between the experimental and theoretical variation of pressure losses with angular position $(\theta)$ with the carbon piston for different combined lengths of up- and downstream pipework in a water flow at $80 \mathrm{dm}^{3} / \mathrm{h}$ : (a) $0.2 \mathrm{~m}$; (b) $20 \mathrm{~m}$.

The theoretical average pressure losses were found to be unaffected by the combined length of up- and downstream pipework. This agreed with the experimental results. However, Fig. 20 shows the detailed pressure losses are given for the carbon piston with combined lengths of up- and downstream pipework of $0.2 \mathrm{~m}$ and $20 \mathrm{~m}$. The agreement of the theoretical model with the experimental results was satisfactory, and the agreement for $2 \mathrm{~m}$ and $10 \mathrm{~m}$ was similar. 
The theoretical pressure losses for four different viscosity liquids: $1 \mathrm{mPa} \mathrm{s}, 5 \mathrm{mPa} \mathrm{s}, 10 \mathrm{mPa} \mathrm{s}$ and $20 \mathrm{mPa}$ s were found to be in good agreement with experimental measurements. (Details of the liquids may be found in Morton et al [3] Table 3.) All theoretical results fell within the uncertainty limits of the experimental data. Fig. 21 show those for $1 \mathrm{mPa}$ s and $20 \mathrm{mPa}$ s with the carbon piston at $80 \mathrm{dm}^{3} / \mathrm{h}$. At higher flow rates and higher viscosities the curves are smoother and in better agreement with the experimental data. There are however, as previously noted with other pressure loss graphs, discrepancies before and after TDC. The detailed pressure losses for $1 \mathrm{mPa}$ s and $20 \mathrm{mPa}$ s with the carbon piston at $16 \mathrm{dm}^{3} / \mathrm{h}$ are given in Fig. 22.

With lower flow rates and viscosities, the agreement was good, and the range of pressure losses and positions of maximum and minimum pressure loss were in agreement with the experimental results. With higher viscosity liquids, the range of pressure losses predicted theoretically was smaller than found experimentally. 


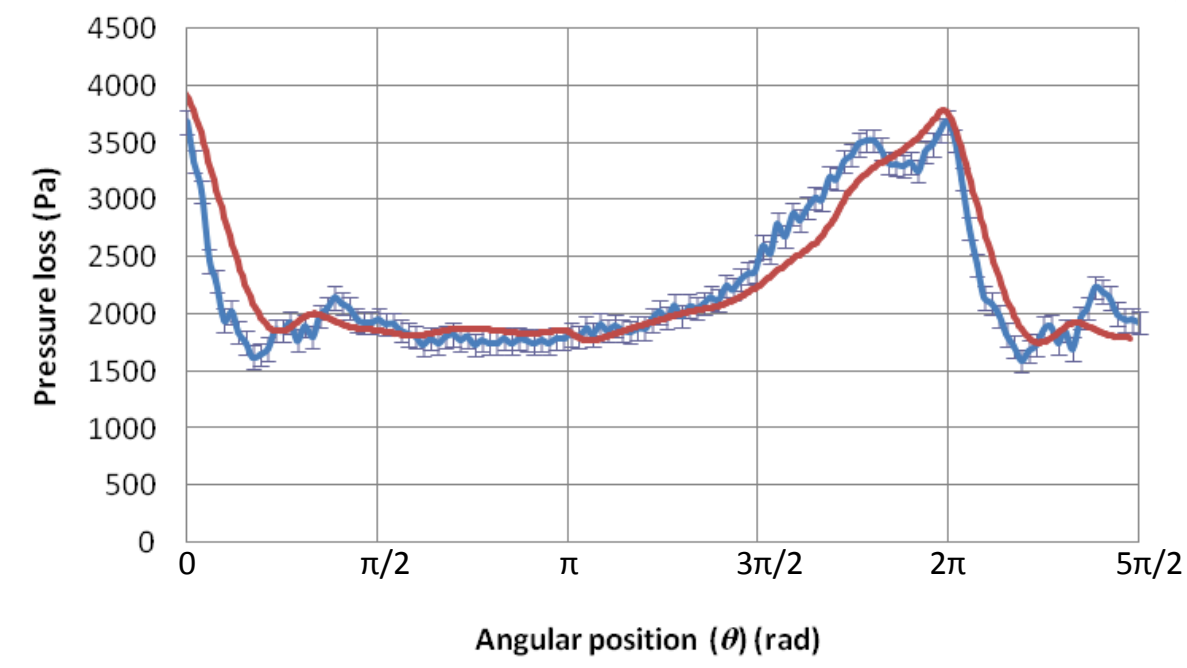

Experimental results Theoretical results

(a)

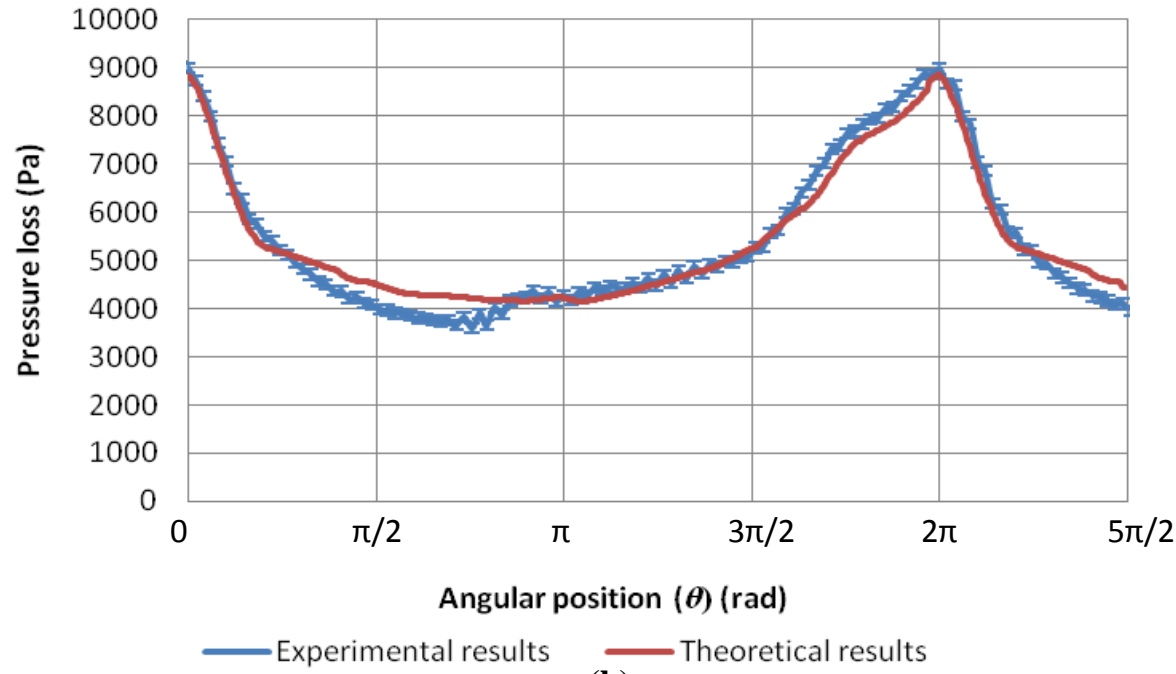

(b)

Fig. 21 Comparison between the experimental and theoretical variation of pressure losses with angular position with the carbon piston for different viscosity fluids at $80 \mathrm{dm}^{3} / \mathrm{h}$ : (a) $1 \mathrm{mPa} \mathrm{s}$; (b) $20 \mathrm{mPa} \mathrm{s}$ 


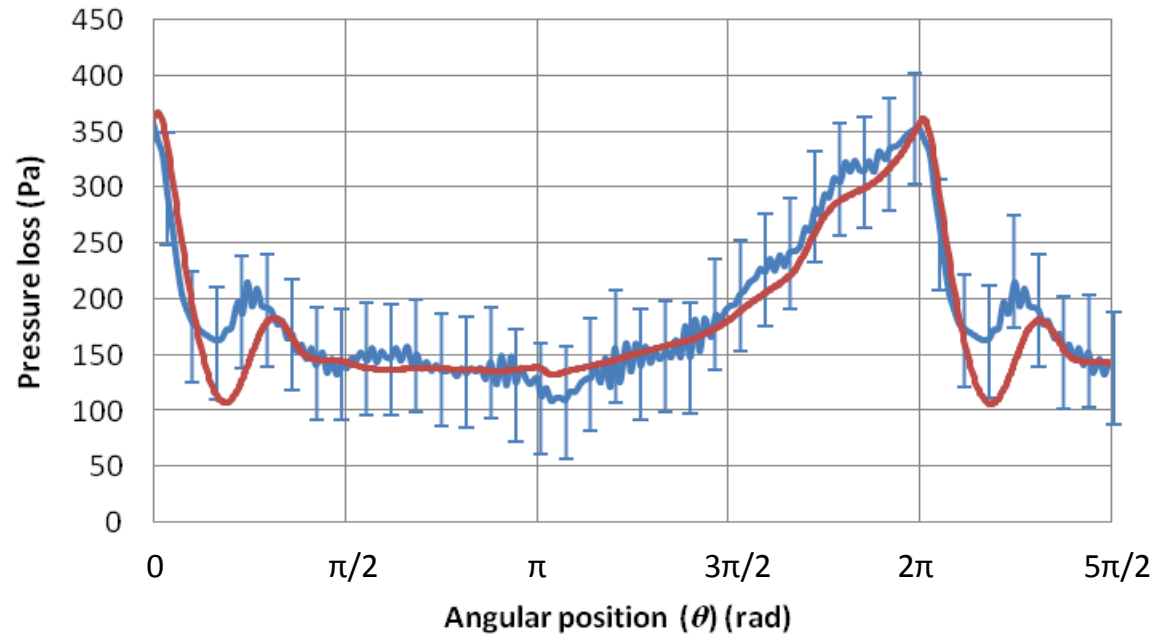

Experimental results Theoretical results

(a)

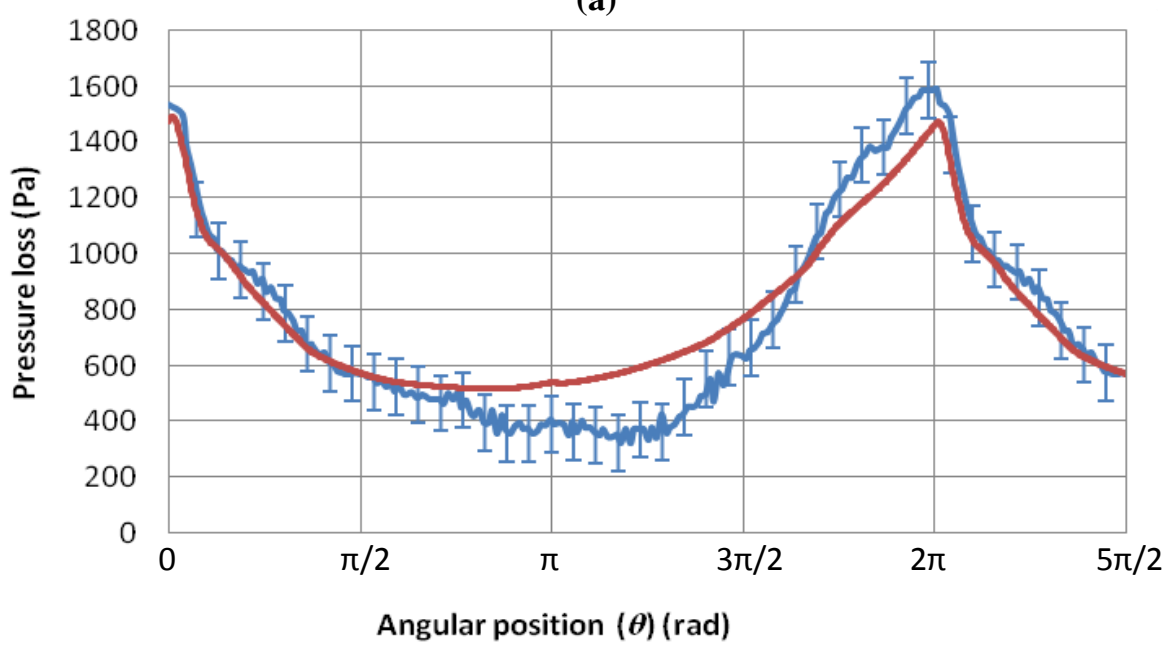

Experimental results (b) Theoretical results

Fig. 22 Comparison between the experimental and theoretical variation of pressure losses with angular position with the carbon piston for different viscosity fluids at $16 \mathrm{dm}^{3} / \mathrm{h}$ : (a) $1 \mathrm{mPa} \mathrm{s}$; (b) $20 \mathrm{mPa} \mathrm{s}$ 


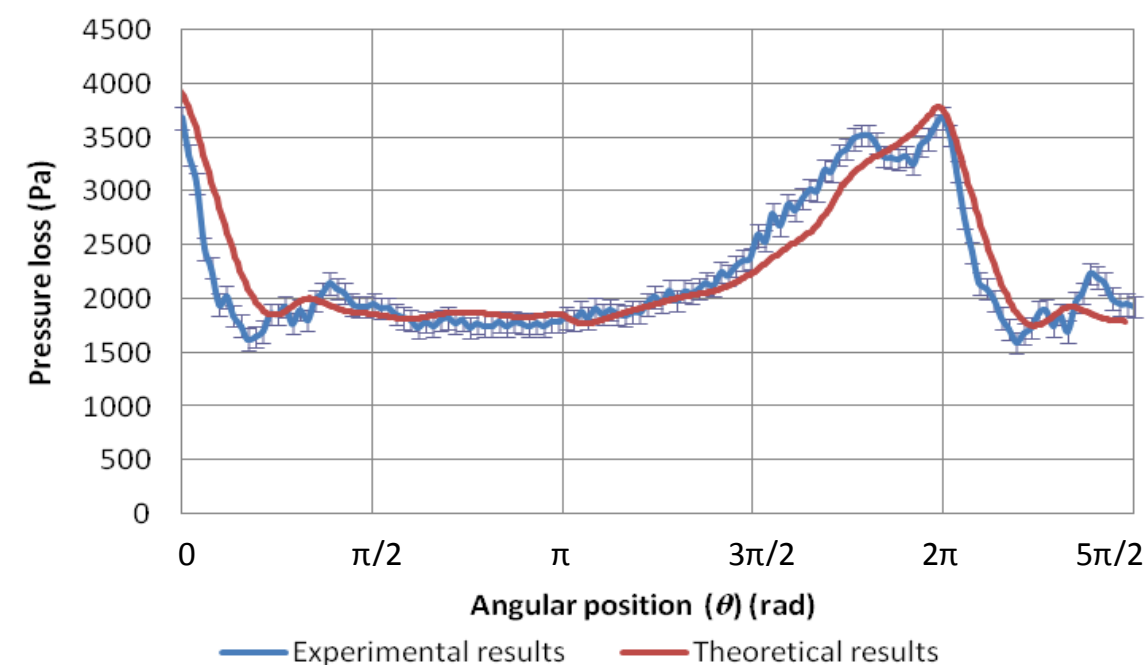

(a)

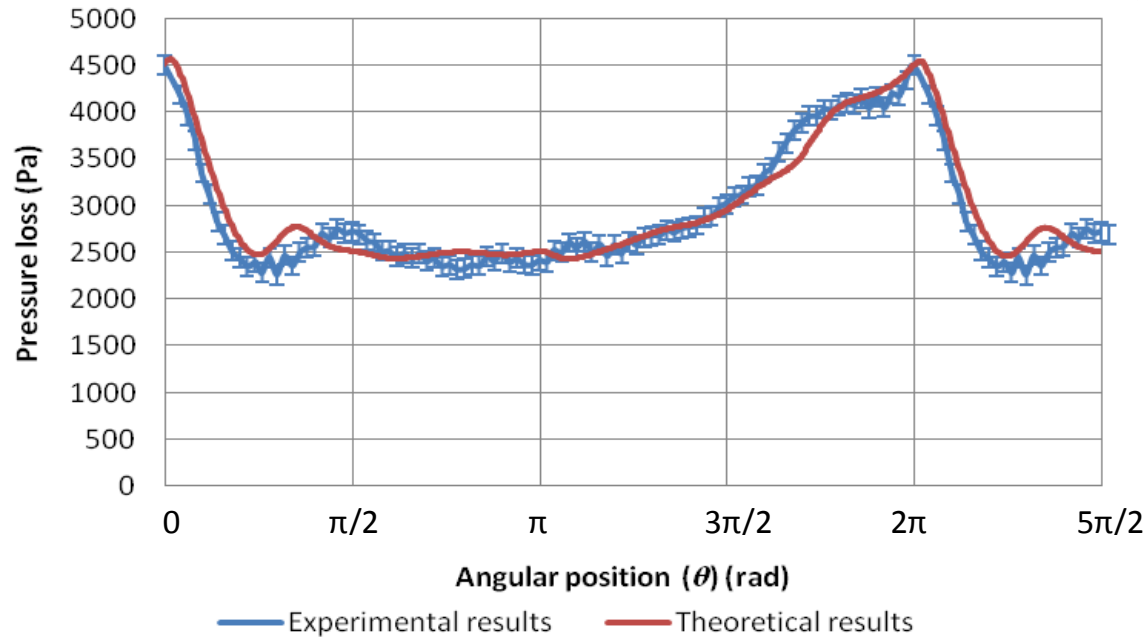

(b)

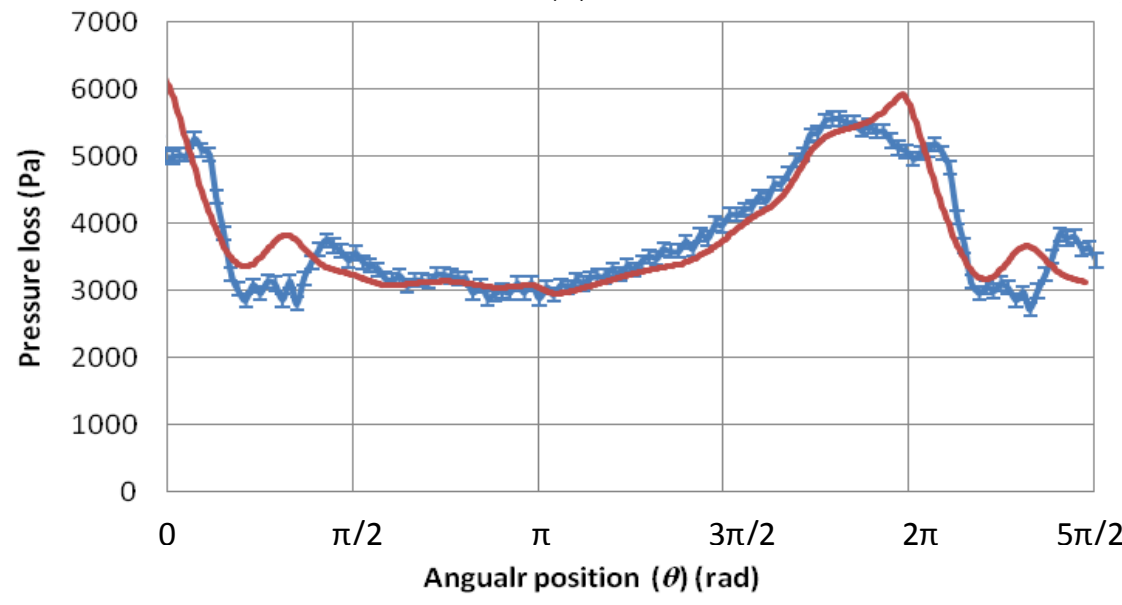

Experimental results Theoretical results

(c)

Fig. 23 Comparison between the experimental and theoretical variation of pressure losses with angular position with the carbon piston with different density liquids at $80 \mathrm{dm}^{3} / \mathrm{h}$ : (a) $780 \mathrm{~kg} / \mathrm{m}^{3}$; (b) $1000 \mathrm{~kg} / \mathrm{m}^{3}$; (c) $1200 \mathrm{~kg} / \mathrm{m}^{3}$. 
Fig. 23 shows the experimental and theoretical results for different density liquids with the same viscosity: $780 \mathrm{~kg} / \mathrm{m}^{3}, 1000 \mathrm{~kg} / \mathrm{m}^{3}$ and $1200 \mathrm{~kg} / \mathrm{m}^{3}$ (achieved by using a white spirit/motor oil mixture, water and salt solution as described in ref. [3]), with the carbon piston at $80 \mathrm{dm}^{3} / \mathrm{h}$. The theoretical pressure losses are in good agreement with the experimental results. The range of pressure losses agreed with the experimental range. Around BDC the agreement was good and the pressure losses fell within the uncertainty limits of the experimental results. Again the agreement was less good before and after TDC.

The pressure losses through the inlet and outlet ducts and across the empty chamber have been estimated, but lack of adequate published data necessitated the use of our experimental data, shown in Fig. 24. The average pressure losses are given in Fig. 24(a) and the detailed pressure losses are given at $80 \mathrm{dm}^{3} / \mathrm{h}$ in Fig. 24(b). The graphs show both the total losses across the flowmeter and the losses without a piston (inlet/outlet losses and loss in the chamber). 


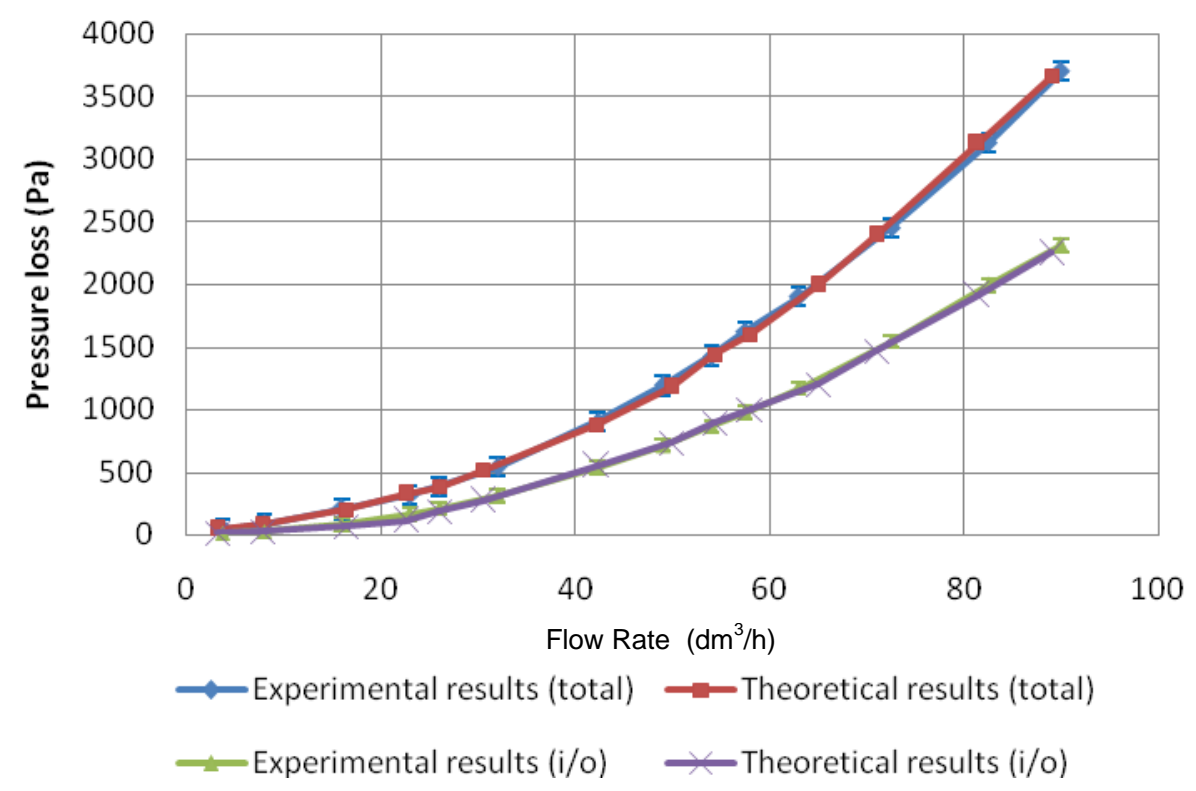

(a)

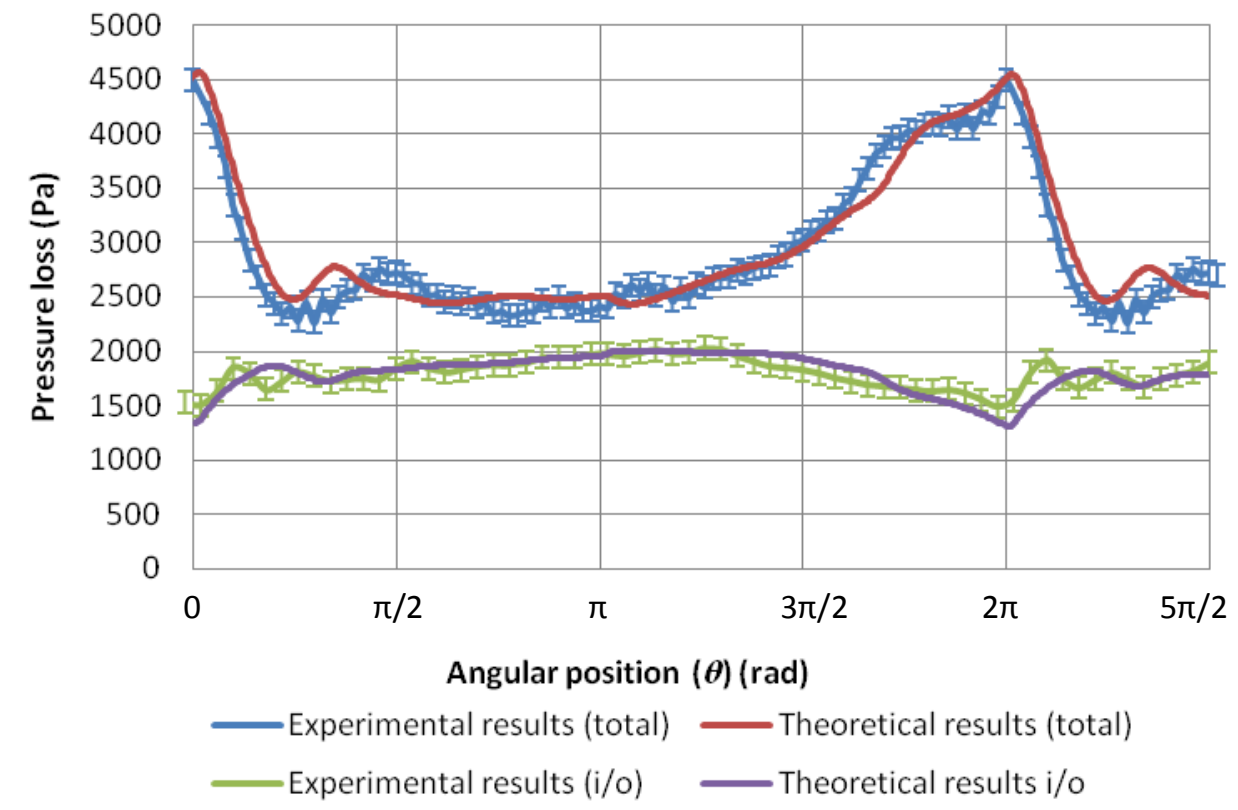

(b)

Fig. 24 Comparison between the experimental and theoretical pressure losses with the carbon piston in the flowmeter, and due to the inlet and outlet ducts only (i.e. with no piston) in a water flow: (a) variation with flow rate; (b) variation with angular position $(\theta)$ at a flow rate of $80 \mathrm{dm}^{3} / \mathrm{h}$. 


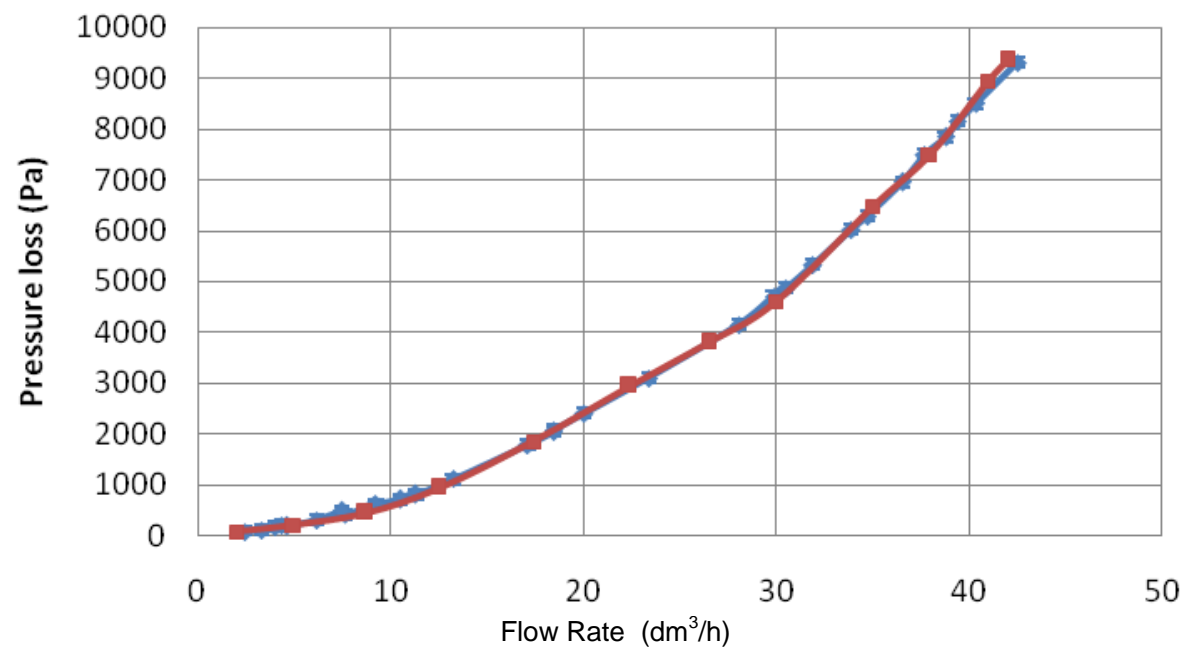

$\longrightarrow$ Experimental results $\quad-$ Theoretical results

(a)

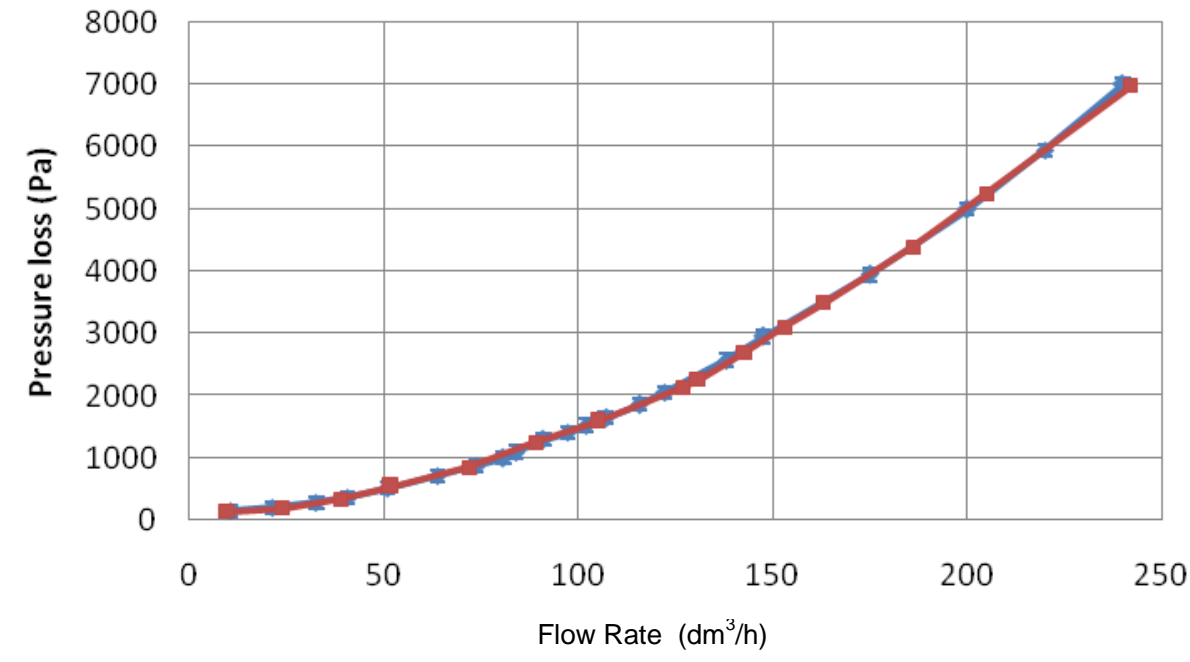

$\multimap$ Experimental results $\rightarrow$ Theoretical results

(b)

Fig. 25 Comparison between the variation of experimental and theoretical average pressure losses with flow rate, for a water flow with carbon pistons in two different meters: (a) LF15; (b) VFF4.

\section{$4.4 \quad$ Pressure losses for the LF15 \& VFF4 meters}

To aid comparison between the three meter sizes, it should be noted that a frequency of $5 \mathrm{~Hz}$ corresponds to a flow rate of $210 \mathrm{dm}^{3} / \mathrm{h}$ for the VFF4, $80 \mathrm{dm}^{3} / \mathrm{h}$ for the MF30 and $35 \mathrm{dm}^{3} / \mathrm{h}$ for the LF15. Fig. 25 shows the average pressure losses for the LF15 and VFF4 meters with the carbon piston. 

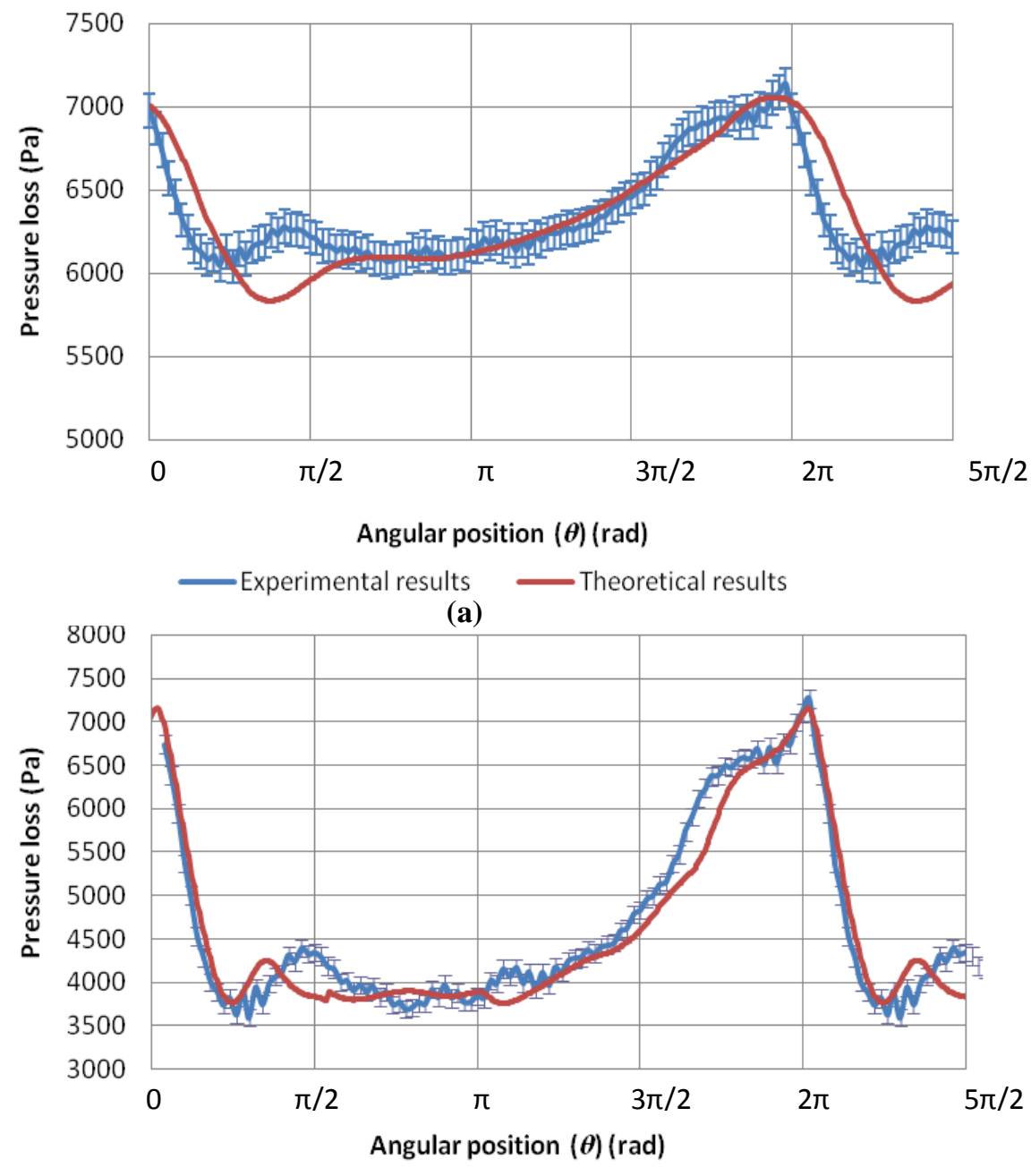

Experimental results Theoretical results

(b)

Fig. 26 Comparison between the variation of experimental and theoretical pressure losses with angular position $(\theta)$ at a frequency of $5 \mathrm{~Hz}$ in a water flow for two different meters: (a) LF15; (b) VFF4.

The pressure losses from the LF15 meter, which is smaller and has a maximum flow rate of $50 \mathrm{dm}^{3} / \mathrm{h}$, were significantly higher than for both the MF30 (maximum flow rate $90 \mathrm{dm}^{3} / \mathrm{h}$ ) and the VFF4 (maximum flow rate $240 \mathrm{dm}^{3} / \mathrm{h}$ ). The theoretical model correctly predicted this. The pressure losses were high because of the smaller diameters of the inlet and outlet ducts in comparison with both the MF30 and VFF4 meters. The pressure losses were proportional to the square of the velocity of the liquid in the inlet and outlet. 


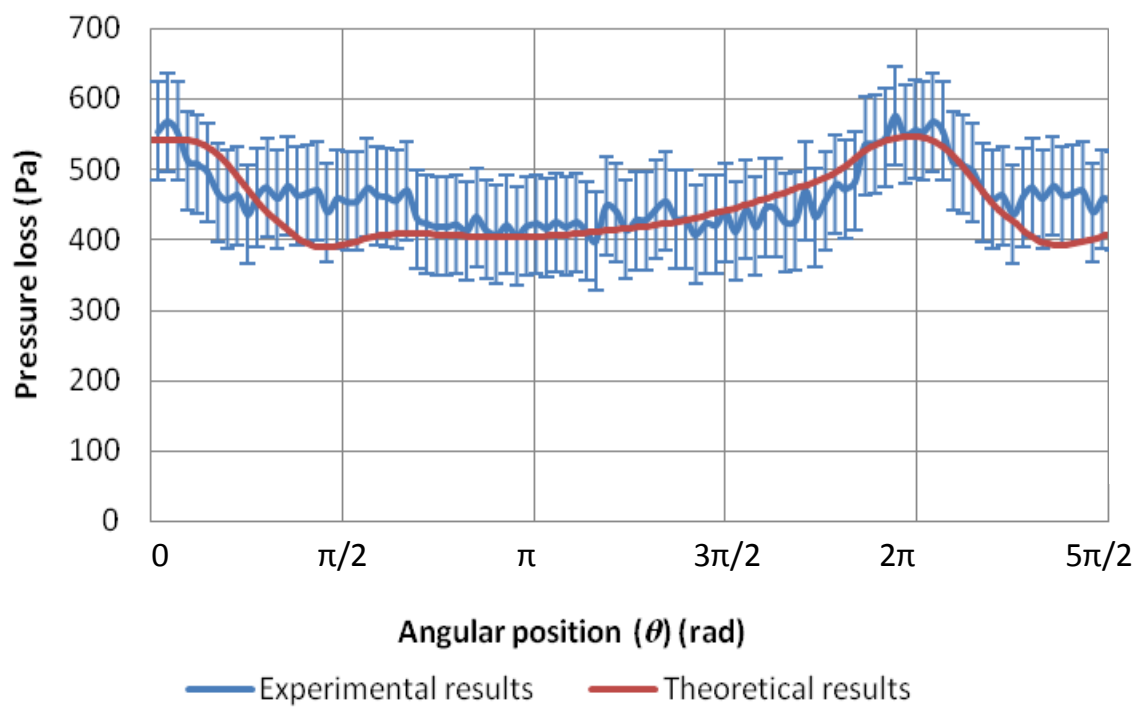

(a)

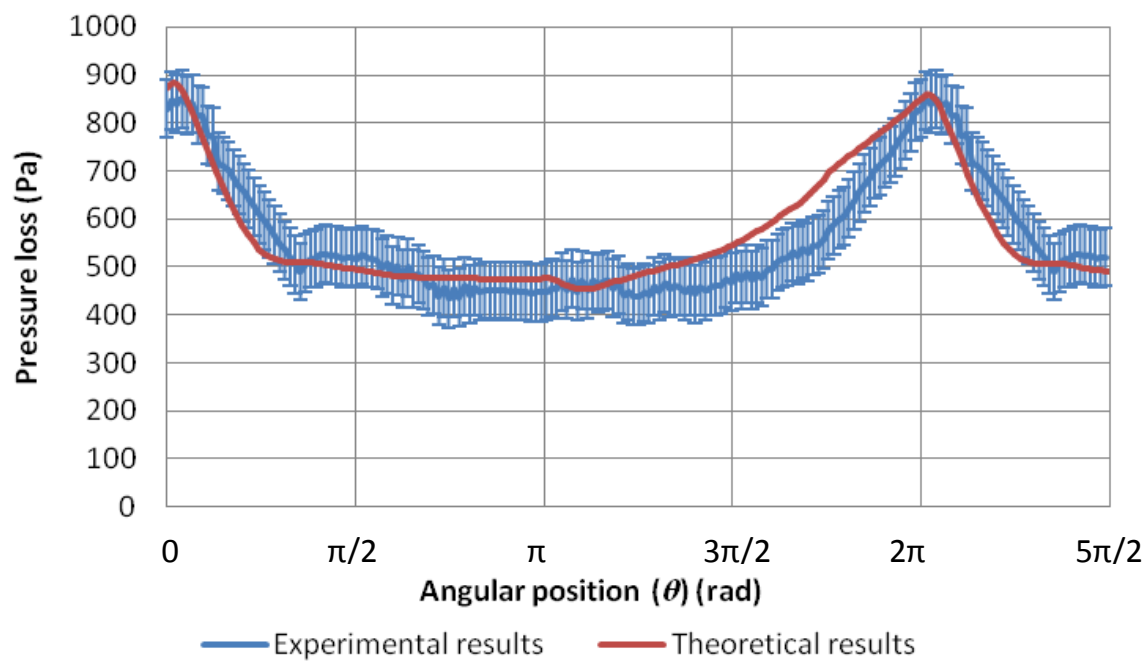

(b)

Fig. 27 Comparison between the variation of experimental and theoretical pressure losses with angular position $(\theta)$ at a frequency of $1 \mathrm{~Hz}$ in a water flow for two different meters: (a) LF15; (b) VFF4.

Fig. 25 shows the agreement for the average pressure losses for both sizes of meter, with only small discrepancies at higher flow rates. More detailed pressure loss variations are given for the LF15 and VFF4 meters for frequencies of $5 \mathrm{~Hz}$ and $1 \mathrm{~Hz}$ in Figs. 26 and 27.

The agreement between the experimental and theoretical results was adequate, although there was less agreement with these results than for those obtained with the MF30 (Fig. 13). The range of pressure losses and the positions for maximum and minimum pressure losses were in good agreement. For the LF15, there was good agreement for most of the oscillation except 
just before and after TDC. At lower flow rates (Fig. 27), the theoretical pressure losses fell within the uncertainty limits of the experimental pressure losses, with only a small discrepancy just before TDC. The VFF4 meter shows less good agreement. At higher flow rates (Fig. 26), although the general curve is similar there were areas that required further investigation.

\section{Discussion}

We have presented the calculation method to solve the equations set out in Morton et al [1] and we have demonstrated, by examples which compare the predictions with the experimental data $[2,3,4]$, the ability of the model to predict the experimental results. In general the model predicts the average and the detailed variations for angular velocity, vertical movement and pressure loss to a satisfactory degree. We have also tested the model for variation in a range of parameters to show that it is consistent in its predictions.

However we have noted some discrepancies in the predictions of the model compared with the data. A general observation is that these are less apparent for higher flow rates when the motion of the piston is smoother.

We note that the model predicts the vertical movement with a good degree of precision which, therefore, suggests that the time stepping calculation is behaving correctly. However, as noted in Morton et al [1] the approximation for the squeeze film torque was of lower precision in some parts of the motion, and this is an element of the model that could potentially be improved. 
Modelling of the effects of the lubrication holes, slots in the skirt and length of connecting pipe work appears to be accurate as shown by the agreement between the model and experimental data.

A perplexing disagreement is that which occurs before TDC. This was also found to be the position of discrepancy for the angular velocity variations, and the cause for this discrepancy requires further investigation. As noted above a deceleration is observed just before TDC and although this is also predicted theoretically, the amount of deceleration predicted is significantly less than that actually observed. It is also apparent at low flow rates $\left(8 \mathrm{dm}^{3} / \mathrm{h}\right.$ or less) that there are smaller scale variations in the angular velocity. The piston appears to have a 'slip-stick' motion that is not predicted by the model. Fig. 12 suggests that the 316SS piston may touch the bottom of the chamber which could lead to such a motion.

The agreement with the experimental data appears to be good for the light PMMA piston movement at high flow rates. Since the contact of the PMMA skirt with the bottom of the chamber will be less than for the more massive pistons, there may be an indication that the friction model could be refined further. Alternatively there may be a further force, not allowed for, but acting on the piston at $\theta=\pi / 2$

There is also a discrepancy after TDC when the pressure has dropped to its lowest point, for instance in Figs. 17(b) \& 25(c) which show the behaviour of the 316SS piston in water and the carbon piston in the most dense liquid, but also elsewhere. This feature does not appear so obvious in the angular velocity plots. It might represent an internal pressure fluctuation due to the sudden deceleration of the piston. 
Thus the experimental results suggest that further refinement of the model may be possible. A further force might be traced back, for example, to the interaction between peg and pin which was observed in wear tests. At lower flow rates, as noted, the motion of the piston has smaller scale variations which may be 'slip-stick' motion. This motion involves periods where the piston moves slowly (sticking) and periods where the piston moves more rapidly (slipping). This motion can be observed in Fig. 8 (b) for the 316SS piston without the low-friction coating. This slip-stick effect is not included in the model, and so the theoretical results remain smooth curves.

This paper has compared the motion and pressure losses obtained experimentally with those obtained theoretically. The theoretical model has shown good agreement with the average pressure losses for the parameters investigated. The largest discrepancy was for the uncoated 316 SS piston, with a discrepancy of around $4 \%$.

The detailed predicted pressure losses also show good agreement with the experimental results. Generally, the theoretical results have the same range of pressure losses and the positions for maximum and minimum pressure loss are in agreement.

The dynamic model ignores the acceleration of any liquid inside and outside the piston which moves with the piston. This has a complex motion that would require CFD methods to analyse. The overall excellent agreement observed between the model predictions and the experimental results suggests that this approximation is justified for nearly all purposes.

The approximation made in our model in the use of equation (7) of Part I, associated with the rocking of the piston and discussed in that paper [1], leads to a small error in the pressure 
drop across the piston which causes an insignificant error in the overall pressure drop across the meter. This is of the same order as the uncertainties in both the modelling and the experimental measurements.

\section{Conclusions}

The model discussed by Morton et al in Part I of this paper [1] has been compared here with experimental data. In general, good agreement is seen, and the behaviour predicted by the model matched that found experimentally.

Experimentally, detailed measurements were obtained for the angular velocity of the piston and the theoretical model was sensitive enough to account for the effects of small changes in flowmeter design, liquid and the combined length of the pipework, which had been noted previously as a cause of changed performance $[1,3]$.

Some of the behaviour, such as an increase in velocity and pressure before TDC, was not so precisely modelled. The agreement was better at higher flow rates, where there were fewer smaller-scale variations. The experimental results suggested that further refinement of the force models, possibly by improving the friction model, would be beneficial.

The paper shows good prediction by the model of both average and detailed pressure losses.

\section{Acknowledgements}

We are grateful to Professor John Williams for advice on frictional models and measurements, and to the technical support staff of the Department of Engineering for assistance with rig construction and software systems. CEM was supported by the UK Engineering and Physical Sciences Research Council (EPSRC) and Litre Meter Limited. 
through an Industrial CASE Studentship. RCB received support from the Gatsby Charitable Foundation. We would also like to acknowledge the support and encouragement provided by Charles Wemyss of Litre Meter Limited.

\section{References}

1. Morton, C. E., Hutchings, I. M. Williams, J. A. and Baker, R. C. Theoretical analysis of the oscillating circular piston positive displacement flowmeter: I - Modelling the forces acting on the piston, Flow Measurement and Instrumentation 60 (2018) 1-16.

2. Morton, C. E. Performance and modelling of the oscillating piston flowmeter. $\mathrm{PhD}$ Thesis, University of Cambridge 2009.

3. Morton, C. E., Hutchings, I. M. and Baker, R. C. Experimental investigation of a positive displacement flowmeter: I - piston movement and pressure losses, Flow Measurement and Instrumentation, 36 (2014) 47-56.

4. Morton, C. E., Baker, R. C. and Hutchings, I. M. Measurement of liquid film thickness by optical fluorescence and its application to an oscillating piston positive displacement flowmeter. Measurement Science and Technology 2011;22:125403 (11pp)

5. Morton, C. E., Baker, R. C. and Hutchings, I. M. Experimental investigation of an oscillating piston positive displacement flowmeter: II - leakage flows and wear tests. Flow Measurement and Instrumentation 36 (2014) 57-63..

6. Szlachta, W. (2005). "Measuring the coefficient of friction". Unpublished Master's thesis, Engineering Department, University of Cambridge. 